Revista Mexicana de Economía y Finanzas Nueva Época

Volumen 14 Número 2, Abril-Junio 2019, pp. 221-243

DOI: https://doi.org/10.21919/remef.v14i2.301

\title{
Efecto de los precios del petróleo en la actividad económica sectorial de México. Análisis para el periodo 2002-2018
}

\author{
Eduardo Saucedo ${ }^{1}$ \\ Tecnológico de Monterrey, México \\ Jorge González ${ }^{2}$ \\ Instituto Econofinanzas, México
}

(Recepción: 14/junio/2018, aceptado: 26/octubre/2018)

\section{Resumen}

Este trabajo analiza el papel que tienen los precios del petróleo en las variaciones de la actividad económica sectorial de México. El periodo analizado es de enero de 2002 a enero 2018, con frecuencia mensual. La metodología propuesta es la de un modelo de Vector Auto Regresivo Estructural (SVAR) para cada sector económico. En dicho modelo se añaden los precios del petróleo, el índice de actividad industrial por sector, los precios al consumidor, la tasa de interés nominal, la actividad económica y el tipo de cambio real como variables de control. Adicionalmente, se construyen funciones impulso respuesta para todos los sectores y sub-sectores industriales. La originalidad del trabajo radica en ser uno de los pioneros en analizar los efectos de precios del petróleo en las diferentes ramas de actividad sectorial en México. Entre los resultados destacados se encuentra que variaciones de los precios del petróleo afectan positivamente a la rama manufacturera. Asimismo, se encuentra que variaciones en el gasto público afectan directamente el sector de la minería. Se concluye que los sectores más ligados al sector externo son los más influenciados ante shocks en los precios del petróleo.

Clasificación JEL: E30, E31, E58, F31, F41

Palabras clave: Petróleo, Actividad Económica Sectorial, México, Impulso Respuesta

\section{Effect of Oil Prices on the Sectoral Economic Activity in Mexico: Analysis for the 2002-2018 Period}

\section{Abstract}

This work analyzes the role of oil prices in the variations of the sectoral economic activity in Mexico. The period analyzed is January 2002 to January 2018, in a monthly frequency. The proposed methodology is that of a Structural Vector Autoregressive (SVAR) model for each economic sector. This model adds the following as control variables: oil prices, industrial activity index by sector, consumer prices, nominal interest rate, economic activity, and real exchange rate. In addition, response impulse functions are built for all industrial sectors and subsectors. The originality of this work lies in it being one of the pioneers in analyzing the effects of oil prices in the different branches of sectoral activity in Mexico. Among the outstanding results is that variations in oil prices positively affect the manufacturing branch. Likewise, it is found that variations in public spending directly affect the mining sector. It is concluded that the sectors most linked to the external sector are the most influenced by shocks in oil prices.

JEL Classification: E30, E31, E58, F31, F41

Keywords: Oil, Sectorial Economic Activity, Mexico, Impulse Response Function

\footnotetext{
${ }^{1}$ EGADE Business School, Tecnológico de Monterrey. (correo electrónico: eduardo.saucedo@itesm.mx). Tel: +52 (81) 86256000 Ext. 6172 .

${ }^{2}$ Instituto Econofinanzas. Monterrey, México. (correo electrónico: jgonzalez@econofinanzas.com) *Sin fuente de financiamiento declarada para el desarrollo de la investigación
} 
REMEF (The Mexican Journal of Economics and Finance) Efecto de los precios del petróleo en la actividad económica sectorial de México.

\section{Introducción}

$\mathrm{Al}$ ser un insumo indispensable tanto para consumidores como para productores, el petróleo ha tenido un papel fundamental en la economía de diversos países. De esta forma, variaciones en el precio de este producto, pueden producir diferentes efectos económicos dependiendo del país en cuestión. Dichos efectos dependen, entre otras cosas, de si se trata de un país que es exportador o importador de petróleo, así como de la relevancia que tiene este insumo en la cadena productiva y en el mercado de bienes finales del país analizado.

Al analizar el precio del petróleo, se encuentra que este ha sido cíclico a lo largo del tiempo. Por ejemplo, la figura 1 muestra que los precios del petróleo West Texas Intermediate (WTI) alcanzaron los 140 dólares por barril en junio de 2008; sin embargo, para enero de 2009 habían caído a 41.73 dólares, provocado por la recesión de la economía global en ese año. No obstante, inmediatamente después de dicha recesión económica, los precios del petróleo se recuperaron y alcanzaron los 120 dólares por barril a finales de 2014, para sufrir posteriormente una fuerte disminución en 2016, llegando así a niveles cercanos a los 30 dólares en febrero de ese año.

Figura 1. Precio del Petróleo (WTI), Dólares por Barril

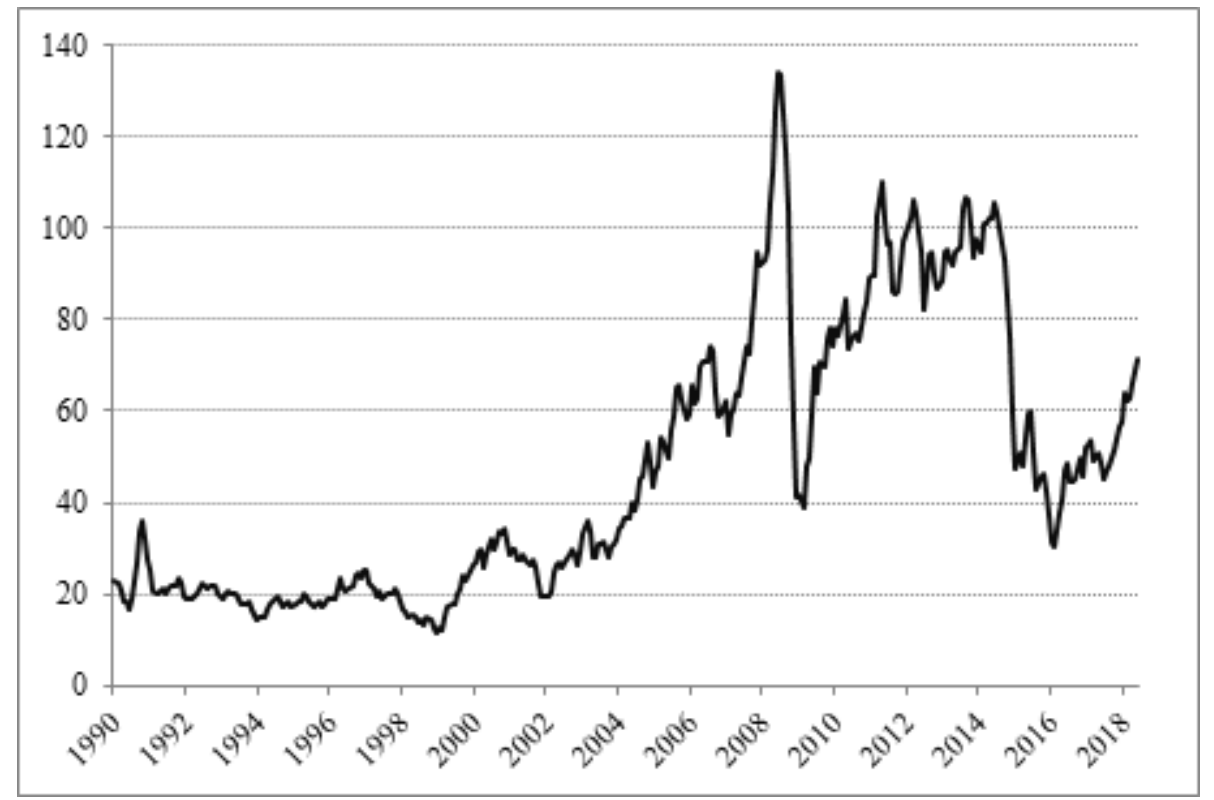

Fuente: Elaboración propia en base a datos de la EIA.

De acuerdo con Sieminski (2014) y Griffin y Teece (2016), el exceso de oferta de crudo ha provocado que los precios del petróleo se hayan mantenido bajos desde principios de 2015 y hasta finales de 2017. Ante esta situación, el cartel de la Organización de Países Exportadores de Petróleo (OPEP) ha realizado esfuerzos para recortar la producción del crudo, esto con la finalidad de darle piso a los precios del crudo. Por otro lado, la alta dependencia de los ingresos petroleros por parte de los países exportadores de petróleo, en conjunto con una disminución en la demanda mundial, ha provocado que diversos sectores en la economía (y países muy dependientes del petróleo) se hayan visto perjudicados por los precios bajos que se han mantenido en forma prolongada.

La figura 2 muestra la producción de petróleo en México durante el periodo 1998-2018. Se puede observar claramente que la producción de petróleo se ha reducido de manera drástica en la última década. Suceso que salta a la vista, ya que ocurre después de alcanzar una producción récord de 3.5 millones de barriles diarios (mdb) en 2004, la cual colocó a 
México como la sexta potencia mundial en la producción de petróleo. Dicha bonanza no fue sostenible y a partir de 2005 la producción de este hidrocarburo comenzó a disminuir continuamente hasta llegar a tener una producción por debajo de los 2 mdb diarios en 2018.

Figura 2. Producción Petróleo en México (Miles de barriles diarios)

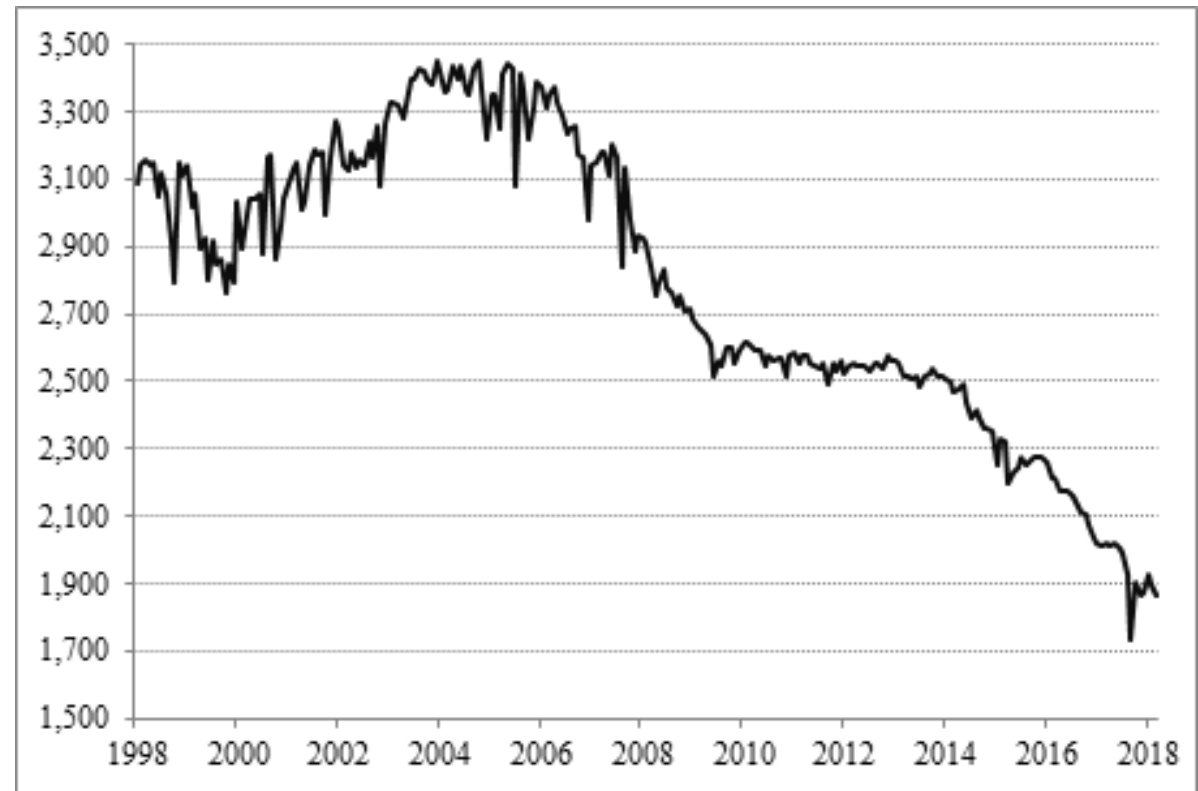

Fuente: Elaboración propia en base a datos del Sistema de Información Energética de la Secretaría de Energía.

Diversa literatura sugiere que los precios del petróleo tienen un papel importante en la economía mexicana. Por un lado, diversos estudios tales como Schwartz, Tijerina y Torre (2002), así como Kohlscheen et al. (2016) indican una relación inversa entre los precios del petróleo y el tipo de cambio; esto es, una caída en los precios internacionales del crudo se ve traducida en una depreciación de la moneda mexicana. Por otro lado, estudios como Lizardo y Mollick (2010) se realizan para diversos países exportadores e importadores de petróleo. Entre los países exportadores se encuentra México y los resultados también indican la existencia de una relación inversa como la antes mencionada.

Segundo, menores precios del petróleo se traducen en un problema para las finanzas públicas, por la disminución en la recepción de ingresos por concepto de exportaciones de petróleo. Campos (2016), además de Hartley y Medlock III (2011), explican a detalle como los ingresos petroleros afectan las finanzas públicas en México. Tercero, diversos sectores de la economía dependientes del petróleo son afectados por una caída en los precios como se explica en Reyes y Benítez (2016).

De esta forma, la manera en que los precios del petróleo pueden afectar a la economía se da a través de distintos canales. Killian (2008) argumenta que los cambios en el precio del crudo afectan el ingreso disponible de los consumidores, y, al ser éste un bien inelástico, reduce la demanda de otros bienes. Adicionalmente, puede existir un efecto de postergación en la compra de bienes durables ante la volatilidad en precios de los energéticos. Estudios como el de Ashgar y Ahmed (2015) y Lanceri (2014) muestran la importancia de las variaciones en los precios del petróleo en la inflación y el tipo de cambio. Otras investigaciones centran su análisis haciendo un comparativo con la "enfermedad holandesa", en la cual la competitividad de los sectores comerciables en la economía se ve afectada al apreciarse el tipo de cambio real. Algunos casos referentes a este tópico son 
REMEF (The Mexican Journal of Economics and Finance) Efecto de los precios del petróleo en la actividad económica sectorial de México.

desarrollados para Latinoamérica por Ramírez (2014) y González (2015).

Como se mencionó anteriormente, en el caso de la economía mexicana, al ser un país exportador de petróleo; los precios de este bien impactan directamente en el tipo de cambio, así como en determinados sectores de la economía. No obstante, a pesar de la importancia de los precios del petróleo y sus efectos en los sectores productivos de la economía mexicana, existe poca literatura al respecto. Por tal motivo, la presente investigación analiza dicha relación. Para ello, se desarrolla una metodología que muestra a los sectores productivos mexicanos más sensibles ante variaciones en los precios del petróleo.

En el siguiente apartado se hace una revisión de la literatura, posteriormente en la sección 2 se describen las variables utilizadas en este estudio. La sección 3 explica la inclusión de los modelos de Vectores Auto Regresivos (VAR) implementados en este trabajo y la sección 4 es sobre la presentación del mismo. Posteriormente, en la sección 5 se exponen los resultados obtenidos y, finalmente, en la sección 6 se presentan las conclusiones de esta investigación.

\section{Literatura Relevante}

Existen diferentes maneras en las que las variaciones de los precios del petróleo pueden afectar el nivel de la actividad económica a nivel sectorial. Un pionero en este tema es Hamilton (1983), quien argumenta que un cambio en los precios del petróleo modifica los precios relativos del capital, trabajo e insumos intermedios, lo que genera a su vez una reasignación de recursos y cambios en las decisiones de inversión.

Para el caso de Estados Unidos, la literatura sobre la relación de los precios del crudo con el crecimiento económico es abundante. Farhani (2012) analiza este hecho a partir de la década de los 70s y encuentra una relación débil entre estos factores, a causa de efectos asimétricos de las variaciones del precio del petróleo. Baumeister y Peersman (2012) encuentran una disminución en la elasticidad de corto de plazo de los precios de petróleo. Los autores mencionan que los precios también reaccionan de manera asimétrica, ya que los efectos difieren de si el shock de oferta es positivo o negativo, provocando así diferentes reacciones en los precios.

De acuerdo con González y Nabiyev (2009), la menor dependencia del petróleo en conjunto con una mejora de los fundamentales de la economía estadounidense, han permitido que los efectos de shocks de petróleo sean limitados. Blanchard y Galsi (2007, 2009) encuentran que la reducción en la magnitud de los shocks económicos se debe en gran medida a la menor participación del petróleo en la actividad económica; así como al aumento en la credibilidad de la política monetaria. Los autores argumentan que dichos factores han ayudado a que las fluctuaciones incidan cada vez menos en el crecimiento económico. No obstante, trabajos como el de Difiglio (2014), encuentra que los periodos de debilidad económica son precedidos por un shock negativo en el precio del petróleo. Mohaddes y Pesaran (2016), muestran que bajos precios del petróleo conducen a bajas tasas de interés, inflación y a un incremento en los precios de las acciones.

Hahn y Mestre (2011), realizan un estudio de los impactos de los precios del petróleo en la Zona Euro. En su estudio, construyen un modelo VAR con volatilidad estocástica y encuentran una relación positiva y significativa de los precios del petróleo con el nivel de precios y la actividad económica, aunque el grado de traspaso es menor respecto a décadas anteriores.

Otros autores que estudian la Zona Euro son Peersman y Van Robays (2009), quienes examinan el mecanismo de transmisión de los precios del petróleo hacia los precios al consumidor y el Producto Interno Bruto (PIB). El estudio hace una comparación con Estados Unidos, en donde se concluye que las variaciones en los precios de los energéticos influyen más que en Europa, región en la que son más importantes los efectos de segundo 
orden, particularmente incrementos de salarios, los cuales afectan la inflación ${ }^{3}$. En Cuñado y Pérez (2003), se examina como impactan los precios del petróleo en la Unión Europea, encontrando que tienen un impacto permanente en la inflación y crean efectos asimétricos en el corto plazo sobre la producción.

Jiménez (2011), analiza el caso de Francia, Alemania, Italia, España, Reino Unido y Estados Unidos y, a través de un SVAR, demuestra como los shocks en los precios del petróleo afectan las economías de dichos países. El trabajo del autor se diferencia de otros al tener en cuenta la importancia del bloque económico para Europa, en donde encuentra un efecto negativo en la producción de los sectores industriales para esta región tras un shock positivo en los precios del petróleo. Además, los agregados monetarios reaccionan contrayéndose, lo que perjudica a la actividad manufacturera de los países.

El petróleo es muy importante para países del Medio Oriente. Por ejemplo, Al-Mawali et al. (2016), encuentra una relación positiva entre el sector petrolero y el PIB de Omán, dicha relación del sector petrolero con los demás sectores tiene una mayor fuerza en los sectores de minería, pesca, educación, salud, bienes raíces, entre otros. De acuerdo con el autor, el sector más influenciado es el del gas natural, lo cual está en línea con el hecho de que las actividades petroleras inciden en $42.6 \%$ del PIB de ese país. Por otro lado, Akram (2011), incluye en su estudio India, Pakistán y Bangladesh, en donde analiza el impacto de los precios del petróleo en el crecimiento económico de estos países. El estudio demuestra que, para el primer año de estudio, la variación del precio no afecta la actividad económica, pero para el segundo año tiene un impacto negativo débil en India, un efecto más negativo en Bangladesh y un efecto positivo para Pakistán.

Para el caso latinoamericano, Pedersen y Ricaurte (2014), examinan en su estudio a Chile, quien se caracteriza por ser un importador neto de petróleo. El ejercicio se extiende para los países de Estados Unidos, China, Japón y algunos países de Europa. Entre los principales resultados se encuentra que los índices de precios reaccionan de manera positiva ante un shock positivo de los precios del petróleo. Respecto al tipo de cambio, éste se deprecia ante un shock de oferta (menor producción) y conduce a una apreciación ante un shock de demanda. Para los otros socios comerciales, se encuentra que los efectos tras un shock de oferta no son significativos. Sin embargo, para los shocks de demanda los impactos son positivos.

González (2015), en una investigación para Colombia, encuentra que cambios positivos en los precios del petróleo afectan a la actividad económica de manera proporcional; pero ante cambios negativos en los precios no se encuentra relación alguna. Otro hallazgo interesante de este estudio es el hecho de que no existe evidencia estadísticamente significativa que relacione los precios del petróleo con el nivel de consumo privado. En este sentido, a nivel sectorial las exportaciones industriales y agrícolas se ven afectadas por una apreciación del peso colombiano. Este es de los pocos estudios que realizan un análisis multisectorial para una misma economía, lo que da un punto de partida de que hay ganadores y perdedores ante shocks en los precios del petróleo. Asimismo, Perilla (2010), estudia el caso de Colombia en un nivel multisectorial. En sus resultados donde incluye precios máximos y mínimos para el petróleo, encuentra efectos asimétricos debido a que el efecto sobre el tipo de cambio favorece a las importaciones y reduce las exportaciones. Adicionalmente, en su estudio encuentra que el efecto final del precio del petróleo en la actividad económica es positivo.

El ruido político, así como temas económicos tienen un efecto importante en la determinación de los precios del petróleo. Lo anterior es demostrado en King et al. (2012), en donde los autores encuentran que las decisiones de la OPEP influyen en los precios del petróleo. Además, no encuentran una relación significativa entre el trading de los especuladores y sus efectos en los precios del petróleo. Por otro lado, Boheman y Maxen (2015),

\footnotetext{
${ }^{3}$ Particularmente, Grecia, Alemania y España son los países más afectados en la inflación. Para el caso de Finlandia un shock de oferta reduce en 0.02 puntos porcentuales la inflación.
} 
REMEF (The Mexican Journal of Economics and Finance)

Efecto de los precios del petróleo en la actividad económica sectorial de México.

estudian sí los países miembros de la OPEP reaccionan de forma distinta a las variaciones en precios del petróleo respecto a los países no-OPEP. Los resultados encontrados en el estudio muestran que los países de la OPEP son más sensibles a las variaciones del precio del petróleo.

En lo referente a la economía mexicana, es importante señalar que es muy poca la literatura existente que mida los impactos de precios del petróleo en la actividad económica. En el 2000, el Fondo Monetario Internacional (IMF) realizó un estudio en donde muestra que un shock de 5 dólares en los precios del petróleo no tiene impacto en el PIB de México, y apenas un impacto de 0.1 puntos porcentuales en la inflación del país. Por otra parte, Sotoudeh y Wothington (2011) realizan una aproximación de cómo distintos países (entre ellos México) reaccionan ante shocks en los precios del petróleo. En su estudio encuentran que, para México, un shock de oferta incide positivamente en la actividad económica, mientras que un shock de demanda tiene un efecto negativo, pero muy cercano a cero.

Valdés (2017), a través de un modelo TGARCH encuentra una relación entre el mercado accionario mexicano y los precios del petróleo para el periodo 2010-2014. La intuición es que es altamente probable incrementos en el rendimiento de las acciones, seguido de aumentos en precios del crudo. Por su parte, Alonso (2017) examina el impacto del precio del crudo para países de la Alianza del Pacífico. Respecto a México, existe una relación positiva entre precios y crecimientos, aunque se diluye en el tiempo, a diferencia de Chile y Colombia. Asimismo, Santillán y Venegas (2015) encuentran una relación positiva para países latinos en el periodo 1990-2014, entre ellos México, entre crecimiento económico y los precios del petróleo Brent y WTI. El impacto se acentúa en la medida que un país es más dependiente de este insumo.

Debido a la escasez de literatura en este tópico para la economía mexicana, el presente trabajo intenta reducir esa brecha y ser uno de los pioneros en medir como las variaciones del precio del petróleo afectan a los distintos sectores de la economía mexicana.

\section{Variables de interés}

Las variables utilizadas en este trabajo incluyen el índice de actividad industrial para las 4 principales ramas económicas en el país (minería, generación de electricidad, suministro de agua y gas, construcción y manufacturas) establecidas por el Instituto Nacional de Estadística y Geografía (INEGI), así como para 29 subramas o sectores que dependen de dichas ramas cuyos datos también provienen del INEGI. Estas clasificaciones se resumen en al anexo 1.1. La variable de precio internacional del petróleo se obtiene de U.S. Energy Information Administration (EIA), y se utiliza el WTI. Adicionalmente, se agregan variables de control tales como, la tasa de interés (cete a 28 días) y el tipo de cambio, el cual tiene incidencia en la actividad económica, ambas variables obtenidas del Banco de México. También se anexa la variable del Indicador General de la Actividad Económica (IGAE), obtenida del INEGI. La tasa anual de inflación se obtiene del INEGI, la cual es utilizada como una variable de control que considera el nivel precios. La frecuencia de todas las variables es mensual y abarca el periodo de enero de 2002 a enero de 2018.

\section{Modelo Econométrico}

Es vasta la literatura en donde se construye un modelo VAR para observar la incidencia de los precios del petróleo sobre la actividad económica de un país. Uno de ellos es Hahn y Mestre (2011), quienes construyen dos modelos con la finalidad de cuantificar cómo reacciona la actividad económica en la Zona Euro ante variaciones en el precio del petróleo. En el modelo que denominan doméstico, desarrollan un modelo VAR donde se incluyen los precios del petróleo, el PIB, la tasa de interés y la inflación. Sin embargo, en el modelo global se incluye la producción mundial de petróleo y un índice de producción industrial global, y, de esta forma, los autores controlan por shocks de oferta y demanda, respectivamente. En lo referente a la presente investigación, esta se centrará únicamente 
en analizar cómo reacciona la actividad económica en distintos sectores y sub-sectores ante variaciones en el precio del petróleo.

Pedersen (2014) desarrolla un modelo VAR en donde se agregan variables endógenas como, el precio y la producción de petróleo, el PIB, el índice de precios, la tasa de interés y el tipo de cambio nominal; todas estas variables son expresadas en logaritmo natural con excepción de la tasa de interés. Asimismo, el precio del petróleo en ese artículo es agregado para controlar los shocks de oferta. En una investigación adicional, Killian (2008) argumenta que no es necesario incluir muchas variables en el modelo si el propósito es estimar de manera consistente como responde un agregado económico ante un shock en el precio del petróleo. Jiménez (2011) estima un SVAR en el cual se anexan las variables enlistadas anteriormente, además de los agregados monetarios. La particularidad de dicho modelo es la imposición de restricciones al momento de estimar el VAR. En el estudio se capta la endogeneidad entre las variables, dejando como exógena la variable del precio del petróleo.

Otro estudio que avala la aplicación de un SVAR para analizar los efectos de los precios del petróleo en la actividad económica es el de Lanceri (2014), donde incluye actividad industrial, tasa de interés, inflación, tipo de cambio y los precios del petróleo, para Estados Unidos, España, Noruega y Argentina. Craveiro (2013) utiliza un VAR para el caso de Portugal, en el cual incluye la inflación, deflactor del PIB, salarios, PIB y empleo, además de los precios del petróleo. Parte de la base de una economía pequeña abierta (al igual que en México) y analiza el impacto de los precios del petróleo en variables domésticas, es decir de manera exógena. Las demás variables permanecen como endógenas.

Este es el punto de partida para esta investigación, la cual es elaborada con datos mensuales y el período analizado es de enero de 2002 a enero de 2018. Las variables están presentadas en la doceava diferencia logarítmica ${ }^{4}$, a excepción de la tasa de interés que está presentada en niveles (pero sí en diferencias). El objeto de esta transformación es simular crecimientos interanuales de las variables. Así, la metodología implementada busca medir el impacto de variaciones en los precios del petróleo en la actividad económica sectorial. Las pruebas de raíz unitaria para las variables en doceava diferencia logarítmica del modelo son presentadas en la tabla 1 .

Tabla 1. Test Raíz Unitaria Variables en Diferencia 12

\begin{tabular}{|l|c|c|c|c|c|c|}
\hline \multicolumn{1}{|c|}{ Variables } & Dfuller & $\begin{array}{c}\text { Dfuller } \\
\text { no constante }\end{array}$ & $\begin{array}{c}\text { Dfuller } \\
\text { tendencia }\end{array}$ & $\begin{array}{c}\text { Rezagos } \\
\text { optimos }\end{array}$ & $\begin{array}{c}\text { Dfuller } \\
\text { rezagos }\end{array}$ & P Perron \\
\hline Industria Total & $-3.30^{* *}$ & $-3.07^{*}$ & $-3.32^{* * *}$ & 1 & $-2.90^{* *}$ & $-3.13^{* *}$ \\
\hline Minería & $-5.36^{*}$ & $-4.83^{*}$ & $-6.50^{*}$ & 3 & -2.1 & $-4.84^{*}$ \\
\hline $\begin{array}{l}\text { Extracción de Petróleo } \\
\text { Gas }\end{array}$ & $-5.48^{*}$ & $-4.50^{*}$ & $-6.60^{*}$ & 3 & -2.17 & $-4.99^{*}$ \\
\hline $\begin{array}{l}\text { Minerales metálicos } \\
\text { y no metálicos }\end{array}$ & $-5.02^{*}$ & $-4.47^{*}$ & $-5.01^{*}$ & 1 & $-4.01^{*}$ & $-4.81^{*}$ \\
\hline $\begin{array}{l}\text { Servicios relacionados } \\
\text { con la minería }\end{array}$ & $-4.73^{*}$ & $-4.41-$ & $-5.97^{*}$ & 1 & $-4.12^{*}$ & $-4.63^{*}$ \\
\hline $\begin{array}{l}\text { Gen. Electr. suministro } \\
\text { gas y agua }\end{array}$ & $-3.35^{* *}$ & $-2.31^{* *}$ & $-3.75^{* *}$ & 2 & $-2.62^{* *}$ & $-3.01^{* *}$ \\
\hline $\begin{array}{l}\text { Gen. Trans. Dist de } \\
\text { energía eléctrica }\end{array}$ & $-3.46^{*}$ & $-2.46^{* *}$ & $-3.91^{* *}$ & 3 & $-3.10^{* *}$ & $-3.24^{* *}$ \\
\hline $\begin{array}{l}\text { Suministro de agua y } \\
\text { suministro de gas }\end{array}$ & -2.05 & $-1.94^{* * *}$ & -2 & 5 & $-6.30^{*}$ & $-3.32^{* *}$ \\
\hline
\end{tabular}

\footnotetext{
${ }^{4}$ Algunos de los autores que utilizan esta metodología son Capistrán (2012) y Cortés (2013), donde usan una diferencia de 12 meses para aproximar crecimientos anuales. Las investigaciones se centran en cómo reacciona la inflación ante cambios en el tipo de cambio, a través de una metodología VAR similar.
} 
REMEF (The Mexican Journal of Economics and Finance) Efecto de los precios del petróleo en la actividad económica sectorial de México. Análisis para el periodo 2002-2018

\begin{tabular}{|c|c|c|c|c|c|c|}
\hline Variables & Dfuller & $\begin{array}{c}\text { Dfuller } \\
\text { no constante }\end{array}$ & $\begin{array}{c}\text { Dfuller } \\
\text { tendencia }\end{array}$ & $\begin{array}{l}\text { Rezagos } \\
\text { óptimos }\end{array}$ & $\begin{array}{l}\text { Dfuller } \\
\text { rezagos }\end{array}$ & P Perron \\
\hline Construcción & $-5.64^{*}$ & $-5.03^{*}$ & $-5.77^{*}$ & 2 & $-3.95^{*}$ & $-5.30^{*}$ \\
\hline Edificación & $-5.86^{*}$ & $-5.68^{*}$ & $-5.85^{*}$ & 2 & $-3.72^{*}$ & $-5.45^{*}$ \\
\hline $\begin{array}{l}\text { Construcción de obras } \\
\text { de ingeniería civil }\end{array}$ & $-2.95^{* *}$ & $-2.91^{*}$ & $-3.79^{* *}$ & 2 & $-2.88^{* *}$ & $-2.78^{* * *}$ \\
\hline $\begin{array}{l}\text { Trabajos } \\
\text { especializados }\end{array}$ & $-5.14^{*}$ & $-4.64^{*}$ & $-5.22^{*}$ & 13 & $-2.59 * * *$ & $-5.38^{*}$ \\
\hline Manufacturas & $-3.03^{* *}$ & $-2.80^{*}$ & -2.96 & 13 & -2.42 & $-3.43^{* *}$ \\
\hline $\begin{array}{l}\text { Industria } \\
\text { alimentaria }\end{array}$ & $-8.08^{*}$ & $-4.34^{*}$ & $-8.10^{*}$ & 5 & $-3.09 * *$ & $-8.37^{*}$ \\
\hline $\begin{array}{l}\text { Industria de las bebidas } \\
\text { y del tabaco }\end{array}$ & $-7.78^{*}$ & $-5.98^{*}$ & $-7.85^{*}$ & 2 & $-5.77^{*}$ & $-7.80^{*}$ \\
\hline $\begin{array}{l}\text { Fabricación de } \\
\text { insumos textiles }\end{array}$ & $-5.58^{*}$ & $-5.48^{*}$ & $-5.68^{*}$ & 14 & $-2.771^{* * *}$ & $-5.69^{*}$ \\
\hline $\begin{array}{l}\text { Fabricación de } \\
\text { productos textiles }\end{array}$ & $-5.85^{*}$ & $-5.84^{*}$ & $-5.89^{*}$ & 13 & $-3.418^{* *}$ & $-5.97^{*}$ \\
\hline $\begin{array}{l}\text { Fabricación de } \\
\text { prendas de vestir }\end{array}$ & $-7.44^{*}$ & $-7.35^{*}$ & $-8.01^{*}$ & 13 & $-4.367^{*}$ & $-8.14^{*}$ \\
\hline $\begin{array}{l}\text { Curtido y acabado } \\
\text { de cuero }\end{array}$ & $-6.56^{*}$ & $-6.41^{*}$ & $-6.48^{*}$ & 13 & $-3.391^{* *}$ & $-7.24^{*}$ \\
\hline $\begin{array}{l}\text { Industria de la } \\
\text { madera }\end{array}$ & $-8.28^{*}$ & $-8.31^{*}$ & $-8.52^{*}$ & 13 & $-3.901^{*}$ & $-9.42^{*}$ \\
\hline $\begin{array}{l}\text { Industria } \\
\text { del papel }\end{array}$ & $-6.11^{*}$ & $-4.19^{*}$ & $-6.07^{*}$ & 13 & $-4.200^{*}$ & $-6.16^{*}$ \\
\hline $\begin{array}{l}\text { Impresión e industrias } \\
\text { conexas }\end{array}$ & $-8.68^{*}$ & $-8.71^{*}$ & $-8.65^{*}$ & 2 & $-5.894^{*}$ & $-8.66^{*}$ \\
\hline $\begin{array}{l}\text { Fab. Prod. derivados } \\
\text { petróleo y carbón }\end{array}$ & $-3.25^{* *}$ & $-2.81^{*}$ & $-4.61^{*}$ & 2 & -1.225 & -2.47 \\
\hline $\begin{array}{l}\text { Industria } \\
\text { química }\end{array}$ & $-6.51^{*}$ & $-6.52^{*}$ & $-7.43^{*}$ & 13 & $-2.55^{* * *}$ & $-7.17^{*}$ \\
\hline $\begin{array}{l}\text { Industria del plástico y } \\
\text { del hule }\end{array}$ & $-4.56^{*}$ & $-4.34^{*}$ & $-4.53^{*}$ & 2 & $-3.06^{* *}$ & $-4.31^{*}$ \\
\hline $\begin{array}{l}\text { Fab. Prod. minerales } \\
\text { no metálicos }\end{array}$ & $-4.73^{*}$ & $-4.64^{*}$ & $-4.72^{*}$ & 1 & $-3.81^{*}$ & $-4.49^{*}$ \\
\hline $\begin{array}{l}\text { Industrias metálicas } \\
\text { básicas }\end{array}$ & $-4.03^{*}$ & $-4.04^{*}$ & $-4.03^{*}$ & 1 & $-3.65^{*}$ & $-4.03^{*}$ \\
\hline $\begin{array}{l}\text { Fabricación de productos } \\
\text { metálicos }\end{array}$ & $-4.82^{*}$ & $-4.74^{*}$ & $-4.82^{*}$ & 13 & $-2.68 * * *$ & $-5.18^{*}$ \\
\hline $\begin{array}{l}\text { Fabricación de } \\
\text { maquinariay equipo }\end{array}$ & $-2.99 * *$ & $-2.93^{*}$ & -2.99 & 13 & $-2.54^{* * *}$ & $-3.45^{*}$ \\
\hline $\begin{array}{l}\text { Fab. Eq. computación, } \\
\text { comunicación }\end{array}$ & $-4.59^{*}$ & $-4.61^{*}$ & -5.11 & 2 & $-3.64^{*}$ & $-4.24^{*}$ \\
\hline $\begin{array}{l}\text { Fabricación de } \\
\text { aparatos eléctricos }\end{array}$ & $-5.89^{*}$ & $-5.90^{*}$ & $-5.89^{*}$ & 1 & $-4.26^{*}$ & $-5.56^{*}$ \\
\hline $\begin{array}{l}\text { Fabricación de } \\
\text { equipo de transporte }\end{array}$ & $-3.53^{*}$ & $-3.34^{*}$ & $-3.54^{* *}$ & 6 & $-5.09^{*}$ & $-3.93^{*}$ \\
\hline $\begin{array}{l}\text { Fabricación de } \\
\text { muebles, equipos }\end{array}$ & $-10.23^{*}$ & $-10.25^{*}$ & $-10.23^{*}$ & 25 & $-3.55^{*}$ & $-9.91^{*}$ \\
\hline $\begin{array}{l}\text { Otras industrias } \\
\text { manufactureras }\end{array}$ & $-9.66^{*}$ & $-8.59^{*}$ & $-9.79^{*}$ & 3 & $-4.20^{*}$ & $-9.82^{*}$ \\
\hline IGAE & $-2.94^{* *}$ & $-2.093^{* *}$ & -2.87 & 1 & $-2.83^{* *}$ & $-2.97^{* *}$ \\
\hline Tipo de Cambio & $-2.57 * * *$ & $-2.367^{* *}$ & -2.48 & 2 & $-3.66^{*}$ & $-3.10^{* *}$ \\
\hline CETES & $-5.25^{*}$ & $-5.393^{*}$ & -4.92 & 14 & -2.19 & $-5.14^{*}$ \\
\hline INPC & -2.18 & -0.372 & -2.08 & 13 & $-3.19^{* *}$ & $-2.74^{* * *}$ \\
\hline WTI & $-2.65 * * *$ & $-2.597^{*}$ & -2.9 & 3 & $-3.73^{*}$ & $-3.33^{* *}$ \\
\hline PEMEX & $-9.99 *$ & $-9.871^{*}$ & $-10.26^{*}$ & 3 & $-3.76^{*}$ & $-10.18^{*}$ \\
\hline
\end{tabular}

Nota: Ho: La variable tiene raíz unitaria. ${ }^{*}$ rechazo de Ho, es decir, estacionario a1 1\%, ${ }^{* *}$ al $5 \%, * * *$ al $10 \%$. 
Los resultados muestran que al realizar pruebas de Dickey Fuller o Phillips Perron, las variables son estacionarias, lo cual indica que se puede realizar la construcción de un modelo VAR.

\section{Modelo VAR}

Se considera un modelo VAR que incluya variables macroeconómicas y variables específicas de la industria. Para ello, se realizaron inicialmente pruebas de cointegración para descartar relaciones de largo plazo. Los resultados de las pruebas de Johansen permiten concluir que no existe una relación de largo plazo. Los resultados se encuentran en el anexo 1.2. Con ello, el VAR queda representado por un vector $Y_{t}=\left[\begin{array}{c}Y_{1 t} \\ Y_{2 t}\end{array}\right] . Y_{1 t}$ conformado por variables macroeconómicas $Y_{1 t}=\left[\Delta_{12} \ln Y_{t-i}, \Delta_{12} \ln \operatorname{In} f_{t-i}, \Delta_{12} R_{t-i}, \Delta_{12} \ln T C_{t-i}, \Delta_{12} \ln O i l_{t-i}\right]$, donde $\mathrm{Y}$ corresponde al índice de actividad económica de México, Inf al índice de precios al consumidor, $R$ al nivel de tipo de interés a 28 días, $T C$ es el tipo de cambio y $O i l$ es el precio internacional del petróleo. $Y_{2 t}$ es un vector que está conformado por variables en específico de la industria. Para este modelo y dada la disponibilidad de datos, solo se incluye el índice de actividad industrial de cada industria listada en INEGI. Adicionalmente, se agrega una variable dummy como variable exógena que capta la crisis económica del 2008-2009. Esto se anexa en el vector $x_{t}$.

Con ello, el modelo propuesto del VAR en su forma reducida es el siguiente:

$$
y_{t}=c+R(L) y_{t}+Z(L) x_{t}+u_{t}
$$

Donde $\mathrm{R}(\mathrm{L})$ y $\mathrm{Z}(\mathrm{L})$ son matrices de polinomios con el operador de rezago $\mathrm{L}$, $u_{t}$ es la generalización de un proceso de ruido blanco con la matriz de varianzas-covarianzas $\Omega=$ $\left[\begin{array}{ll}\Omega_{11} & \Omega_{12} \\ \Omega_{21} & \Omega_{22}\end{array}\right]$. Adicionalmente, se impone que cambios en las variables macroeconómicas pueden impactar al sector industrial, pero no a los precios del petróleo. En el anexo 1.3, se puede consultar pruebas de exogeneidad que validad esta postura. Similar a lo presentado en Jiménez (2011), también se especifica que una industria en particular no es individualmente capaz de afectar la economía en su totalidad. En su forma matricial, esto significa que:

$$
\left[\begin{array}{l}
Y_{1 t} \\
Y_{2 t}
\end{array}\right]=\left[\begin{array}{l}
c_{1} \\
c_{2}
\end{array}\right]+\left[\begin{array}{cc}
R_{11}(L) & 0 \\
R_{21}(L) & R_{22}(L)
\end{array}\right]\left[\begin{array}{l}
Y_{1 t} \\
Y_{2 t}
\end{array}\right]+\left[\begin{array}{l}
u_{1 t} \\
u_{2 t}
\end{array}\right]
$$

El VAR estructural implica que las perturbaciones de $u_{t}$ estan relacionadas a shocks $\varepsilon_{t}$ en variables macroeconómicas a través de la matriz $A_{0}$, tal que: $A_{0} u_{t}=\varepsilon_{t}$. Siguiendo la metodología de Jiménez (2011), se propone que la matriz $A_{0}$ sea de bloque recursivo, es decir, las variables macroeconómicas no son contemporáneamente afectadas por la actividad industrial de una industria en específico. Así, de esta forma El VAR estructural queda especificado de la siguiente manera:

$$
\left[\begin{array}{cc}
A_{11}^{0} & 0 \\
A_{21}^{0} & A_{22}^{0}
\end{array}\right]\left[\begin{array}{l}
u_{1 t} \\
u_{2 t}
\end{array}\right]=\left[\begin{array}{l}
\varepsilon_{1 t} \\
\varepsilon_{2 t}
\end{array}\right]
$$

Donde $\varepsilon_{t}$ es un vector de ruido blanco con la matriz de varianza-covarianza. Se asume que la matriz $A_{0}$ es cuadrada e invertible. Se utiliza una estructura no recursiva, y esto asume restricciones en los efectos contemporáneos tras shocks estructurales. Con ello, la matriz $A_{0}$ queda representada de la siguiente manera ${ }^{5}$ :

\footnotetext{
${ }^{5}$ Los resultados son robustos para otras identificaciones, al no presentarse grandes cambios en las estimaciones. Por limitaciones de espacio no se presentan otras identificaciones. Consulte con los autores para más información.
} 
REMEF (The Mexican Journal of Economics and Finance) Efecto de los precios del petróleo en la actividad económica sectorial de México.

$$
\left[\begin{array}{cccccc}
a_{1} & 0 & a_{2} & 0 & a_{3} & 0 \\
a_{4} & a_{5} & 0 & a_{6} & a_{7} & 0 \\
0 & 0 & a_{8} & a_{9} & a_{10} & 0 \\
a_{11} & a_{12} & a_{13} & a_{14} & a_{15} & 0 \\
0 & 0 & 0 & 0 & a_{16} & 0 \\
a_{17} & a_{18} & a_{19} & a_{20} & a_{21} & a_{22}
\end{array}\right]\left\lfloor\begin{array}{c}
u_{t}^{y} \\
u_{t}^{i n f} \\
u_{t}^{r} \\
u_{t}^{t c} \\
u_{t}^{\text {oil }} \\
u_{t}^{y_{j}}
\end{array}\right]=\left[\begin{array}{c}
\varepsilon_{t}^{y} \\
\varepsilon_{t}^{i n f} \\
\varepsilon_{t}^{r} \\
\varepsilon_{t}^{t c} \\
\varepsilon_{t}^{\text {oil }} \\
\varepsilon_{t}^{y_{j}}
\end{array}\right]
$$

De acuerdo con la ecuación (4), es posible suponer que la actividad económica total de la economía pueda ser contemporáneamente afectada por shocks en la tasa de interés y en los precios del petróleo. Posteriormente, la inflación se vea afectada por shocks en la actividad económica, tasas de interés y tipo de cambio. La tercera ecuación representa la acción de la política monetaria. El Banco Central impone la tasa de interés después de ver los shocks en tipo de cambio y precios del petróleo, los cuales no responden contemporáneamente a los shocks en actividad económica e inflación. La razón de esto es que el Banco Central analiza estos datos con un rezago. Así, de esta forma se permite que el tipo de cambio reaccione inmediatamente ante shocks en variables macroeconómicas.

Al ser México una economía pequeña, mantenemos los shocks en precios del petróleo como exógenos, es decir, las variables macroeconómicas son influenciadas por cambios en el precio del crudo, pero cambios en variables mexicanas no afectan los precios internacionales del petróleo. Finalmente, la producción industrial de cada sector responde a cambios en las demás variables, pero por su tamaño relativo en la economía no puede impactar a las demás. Con estas especificaciones, imponemos restricciones de un valor de cero a varios coeficientes en las ecuaciones de la matriz $A_{0}$.

Una vez estimado el VAR estructural ${ }^{6}$ por medio del proceso de máxima verosimilitud, se construyen funciones de impulso respuesta acumuladas después de un shock unitario en los precios del petróleo sobre la actividad sectorial de cada industria; posteriormente se presentan intervalos de confianza del $95 \%$. Asimismo, se propone un plazo de análisis de 36 meses después del shock. Por limitaciones de espacio, en el texto se presentarán las industrias principales y el resto de las industrias se encuentran en el anexo 1.4.

\section{Resultados}

\subsection{Industria Total}

En primera instancia, se estudiará el impacto de un shock unitario en el precio del petróleo y como este repercute en la actividad industrial y en diversas variables económicas. Posteriormente, el estudio se centra en las ramas económicas sectoriales más importantes.

\footnotetext{
${ }^{6}$ Con excepción del modelo para fabricación de productos metálicos (2), todos los modelos VAR se le incluyó un rezago en las estimaciones. Para ello nos basamos en el criterio de Schwartz, que en general era el criterio que presentaba menor número de rezagos. También se verifico mediante la prueba de LM Test la presencia de autocorrelación. No se encuentra evidencia significativa de ello. Por cuestiones de espacio no se presentan estos resultados en el estudio.
} 
Figura 3. Impulso Respuesta Industria Total Industria Total

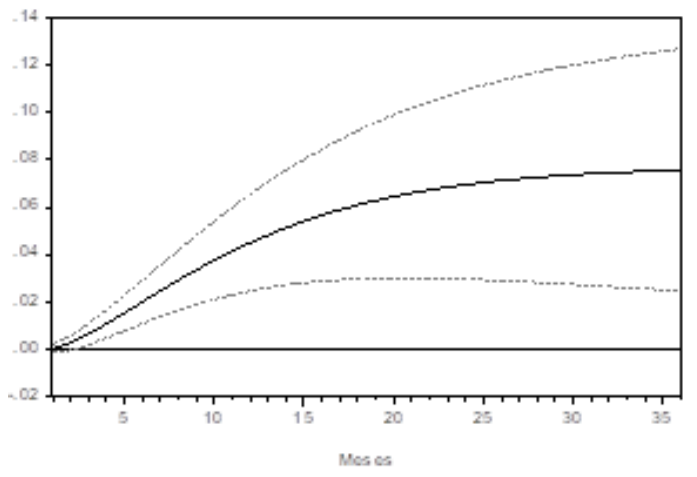

Fuente: Elaboración propia.

Como se puede observar en la figura 3, la actividad industrial reacciona favorablemente a un shock positivo a los precios del petróleo. La forma de presentarlo es a través de una función de impulso respuesta acumulada. Después de 12 meses de la perturbación inicial, el impacto acumulado sobre la actividad industrial es de 0.04 puntos porcentuales y para los 36 meses, el efecto acumula 0.08 puntos porcentuales. Las líneas punteadas en la gráfica representan el intervalo de confianza al $95 \%$. Con ello, se muestra que el efecto es estadísticamente distinto de cero para el horizonte de plazo señalado.

El impacto positivo de un aumento en precios sobre la actividad industrial puede parecer contra intuitiva, ya que, normalmente se pensaría que un encarecimiento de un insumo tan importante afectaría la actividad económica y sectorial. Algunas de las razones para refutar esta idea es que el aumento del precio se refleja en una mayor entrada de dólares para la economía, mejorando así la balanza de pagos. Para 2018, las exportaciones petroleras representan $7 \%$ de las exportaciones totales, un volumen no despreciable considerando el tamaño de la economía mexicana. Los sectores más dependientes del exterior se benefician de esta dinámica. Es de esperarse, que el aumento de las divisas genere un aumento de los términos de intercambio y esto a su vez afecte la demanda de bienes intermedios, los cuales impactan directamente el crecimiento del sector industrial. Asimismo, mejorarían los ingresos fiscales, con lo cual se tendrían efectos indirectos en la actividad económica. Alarco (2006), es uno de los autores que encuentra una relación positiva entre precios del petróleo y crecimiento económico.

El efecto sobre el tipo de cambio es significativo y negativo. La idea de una apreciación cambiaria es que un aumento en el precio del crudo beneficia las finanzas públicas del país, esto se da al acaparar mayores ingresos provenientes por la venta de crudo, con lo cual mejora su situación comercial. Esta situación además se da principalmente en países latinoamericanos (González (2015)), como es el caso de Colombia.

Figura 4. Impulso Respuesta sobre Tipo de Cambio, Inflación y Tasa de Interés

Tipo de Cambio

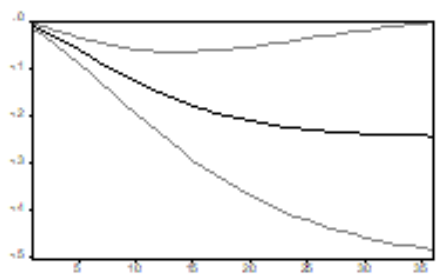

\section{Inflación}

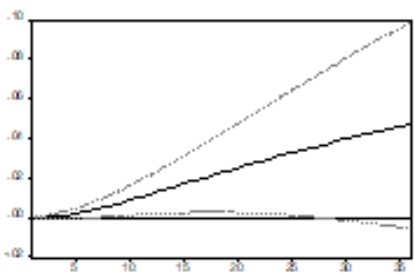

Fuente: Elaboración propia.
Tasa de Interés

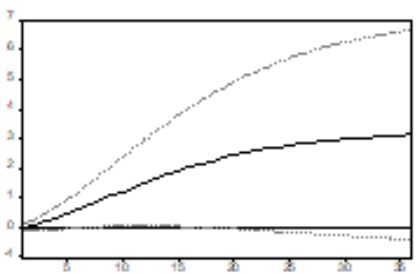


REMEF (The Mexican Journal of Economics and Finance) Efecto de los precios del petróleo en la actividad económica sectorial de México.

La figura 4, muestra evidencia sobre el Impulso Respuesta sobre el tipo de cambio, inflación y tasa de interés, la gráfica muestra adicionalmente que el efecto en la inflación es significativa y positiva, aunque en términos generales, pequeña ${ }^{7}$. Cabe mencionar que los resultados dejan de ser significativos al $5 \%$ alrededor del mes veintiséis. El efecto acumulado oscila alrededor de 0.03 puntos porcentuales en la inflación, ante un shock unitario del petróleo. Adicionalmente, el efecto sobre la tasa de interés es positivo. Después de 12 meses la tasa de interés del cete a 28 días aumenta 1.51\%. Los resultados son significativos hasta el mes dieciocho, donde acumula un incremento del $2.3 \%$ en la tasa. Este hecho se puede deber a que ante un aumento del precio del petróleo y los riesgos que ejerce sobre la inflación, la autoridad monetaria reacciona elevando la tasa de interés, y así mitiga las presiones en el nivel de precios.

Los efectos finales quedan resumidos en la siguiente tabla:

Tabla 2. Impacto en Variables Macroeconómicas Tras Shock Unitario (1\%) en Petróleo

\begin{tabular}{|l|c|c|c|c|}
\hline & $\mathbf{6}$ meses & 12 meses & 24 meses & 36 meses \\
\hline Actividad Económica & $0.02^{*}$ & $0.04^{*}$ & $0.07^{*}$ & $0.08^{*}$ \\
\hline Inflación & $0.00^{*}$ & $0.01^{*}$ & $0.03^{*}$ & 0.05 \\
\hline Tasa de Interés & $0.60^{*}$ & $1.52^{*}$ & 2.72 & 3.13 \\
\hline Tipo de Cambio & $-0.08^{*}$ & $-0.15^{*}$ & $-0.23^{*}$ & -0.24 \\
\hline
\end{tabular}

\subsection{Electricidad y Suministro de Agua}

El sector de la generación y distribución de electricidad tiene un impacto positivo ante un shock unitario del precio internacional del petróleo. La figura 5 muestra que después de 36 meses el impacto en la actividad económica es de 0.08 puntos porcentuales. No obstante, el sector de suministro de agua y gas tiene un impacto negativo ante el mismo shock.

Figura 5. Impulso Respuesta Generación electricidad y suministro agua y gas Generación Electricidad

Suministro Agua y Gas
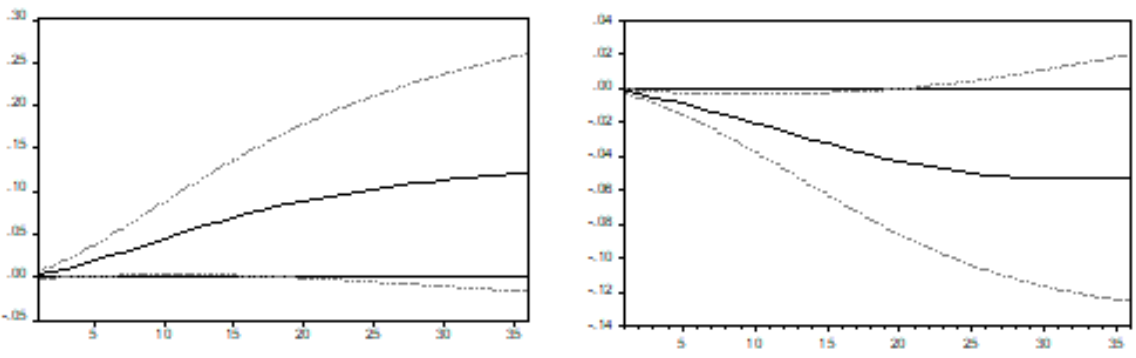

Fuente: Elaboración propia.

La figura 5 muestra que el shock se estabiliza alrededor del mes treinta e implica una disminución de alrededor de 0.05 puntos porcentuales después de 36 meses. Para ver el impacto total en la industria puede consultarse el anexo 1.4 que engloba la totalidad de las industrias, en donde los resultados son el agregado de las dos subramas presentadas abajo. En la tabla 3 se resumen los impactos en la actividad sectorial tras un shock unitario en los precios del crudo.

\footnotetext{
${ }^{7}$ Para el caso mexicano, González y Saucedo (2018) encuentran que los efectos de un shock externo en inflación han sido pequeños y significativos en los últimos años; esto en gran medida gracias a la adopción de un esquema de objetivos de inflación adoptado por Banxico desde 2001.
} 
Tabla 3. Impacto en industrias electricidad, suministro agua y gas

\begin{tabular}{|l|c|c|c|c|}
\hline & $\mathbf{6}$ meses & $\mathbf{1 2}$ meses & $\mathbf{2 4}$ meses & $\mathbf{3 6}$ meses \\
\hline $\begin{array}{l}\text { Gen. Electricidad, sumin. } \\
\text { agua y gas }\end{array}$ & $0.01^{*}$ & $0.04^{*}$ & 0.06 & 0.08 \\
\hline Generación electricidad & $0.02^{*}$ & $0.06^{*}$ & $0.10^{*}$ & 0.12 \\
\hline Suministro agua y gas & $-0.01^{*}$ & $-0.03^{*}$ & $-0.05^{*}$ & -0.05 \\
\hline
\end{tabular}

Como se ve, los efectos de un aumento de los precios del petróleo en los sectores de generación de electricidad y suministro de agua y gas son significativos hasta el mes 24, aunque su efecto sobre la actividad es pequeño.

\subsection{Construcción}

Los impactos en el sector de la construcción a nivel agregado son positivos, tras un shock unitario en el precio del petróleo. Prácticamente la significancia de los resultados recae en la sub-rama de la edificación (que acapara el $70 \%$ del total de la producción de la construcción), que se beneficia de los efectos indirectos tras mejoría de balanza de pagos y efectos multiplicadores en la economía.

Figura 6. Impulso Respuesta Sector Construcción

Construcción

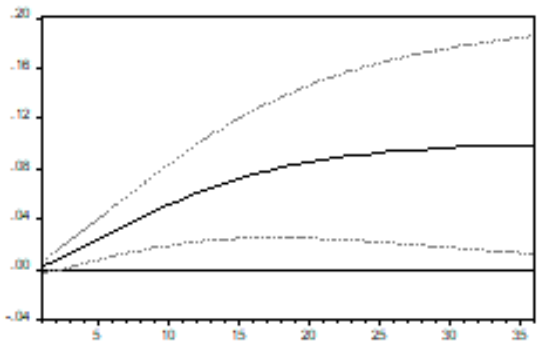

\section{Edificación}

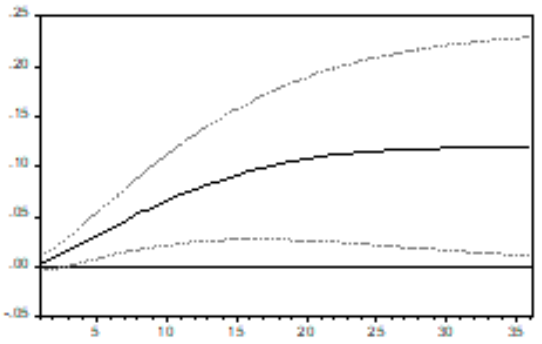

Fuente: Elaboración propia.

La figura 6 muestra además la significancia de la función de impulso respuesta, en donde los intervalos de confianza no tocan el valor de cero, es decir, el efecto del petróleo en la actividad de construcción y edificación es significativo. Además el efecto tiende a normalizarse tras el mes 24.

Tabla 4. Impacto en Industria Construcción

\begin{tabular}{|l|c|c|c|c|}
\hline \multicolumn{1}{|c|}{ Sector } & $\mathbf{6}$ meses & $\mathbf{1 2}$ meses & $\mathbf{2 4}$ meses & $\mathbf{3 6}$ meses \\
\hline Construcción & $0.03^{*}$ & $0.06^{*}$ & $0.09^{*}$ & $0.10^{*}$ \\
\hline Edificación & $0.04^{*}$ & $0.08^{*}$ & $0.11^{*}$ & $0.12^{*}$ \\
\hline \multicolumn{5}{|c}{ Nota: * significativo al $5 \%}$.
\end{tabular}

De acuerdo a la tabla 4 se puede ver que después de 12 meses del impacto acumulado en la actividad sectorial, el impacto es de 0.06 puntos porcentuales. En el anexo 1.4 se puede observar que los impactos en la construcción de obras de ingeniería civil y trabajos especializados en la construcción no son significativos. Particularmente, estas obras son enfocadas en drenaje, puentes, carreteras, las cuales son muy dependientes del gasto público, por lo que shocks en precios del crudo tendrían impactos limitados. La tabla 4 resume los impactos en este sector tras el shock en precios.

\subsection{Manufacturas}

El papel que tiene el petróleo en el sector manufacturero es relevante. De acuerdo con las 
REMEF (The Mexican Journal of Economics and Finance) Efecto de los precios del petróleo en la actividad económica sectorial de México.

estimaciones, este sector representa el $15.7 \%$ del PIB de la economía mexicana (dato al primer trimestre de 2018, calculado como el cociente de PIB Manufacturero/PIB Total), por lo que variaciones en este sector, se espera que afecten la actividad económica en general. Adicionalmente, existe una diversidad de subsectores dentro de este sector, lo que implica que los impactos serán heterogéneos y serán variado dependiendo que tan relacionado este el subsector con el petróleo.

Las manufacturas son el principal sector industrial que se beneficia de un aumento en los precios del crudo. Muchas de las ramas manufactureras se encuentran muy ligadas al sector exportador y son sensibles a los movimientos de los precios de los commodities. De igual manera, existe heterogeneidad dentro de las manufacturas y existen sub-ramas que son más relevantes que otras. La industria alimentaria, productos textiles, industria química, la fabricación de productos a base de minerales no metálicos, las industrias metálicas, productos metálicos, maquinaria y equipo, equipos de computación y fabricación de equipos de transporte resultan ser los subsectores que responden a variaciones en el precio del crudo. El resto de las industrias manufactureras no tienen efectos significativos tras un shock en precios.

Figura 7. Impulso Respuesta Manufacturas Manutacturas

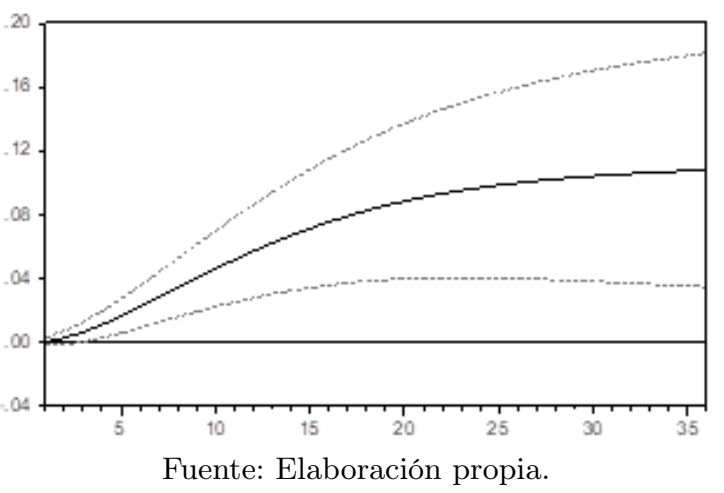

La figura 7 muestra que el efecto de los precios del petróleo en la actividad manufacturera es significativo (distinto de cero) para cualquier mes después del shock. Tras 36 meses del impacto inicial, el efecto sobre las manufacturas es de $0.11 \%$. En la tabla 5 se resume el impacto acumulado de un shock unitario en el precio internacional del petróleo sobre las ramas manufactureras en las que se encuentra significancia estadística. En el anexo 1.4 se presentan las funciones impulso respuesta de todas las ramas, sean o no significativas.

Tabla 5. Impacto Industria Manufacturera

\begin{tabular}{|l|c|c|c|c|}
\hline \multicolumn{1}{|c|}{ Sector } & $\mathbf{6} \mathbf{~ m}$ & $\mathbf{1 2} \mathbf{~ m}$ & $\mathbf{2 4} \mathbf{~ m}$ & $\mathbf{3 6} \mathbf{~ m}$ \\
\hline Manufacturas & $0.02^{*}$ & $0.06^{*}$ & $0.10^{*}$ & $0.11^{*}$ \\
\hline Industria Alim. & $0.00^{*}$ & $0.01^{*}$ & $0.02^{*}$ & 0.02 \\
\hline Productos Textiles & $-0.04^{*}$ & -0.06 & -0.06 & -0.05 \\
\hline Industria Química & $0.02^{*}$ & $0.04^{*}$ & $0.04^{*}$ & 0.04 \\
\hline Min. no Metálicos & 0.01 & 0.03 & $0.06^{*}$ & $0.07^{*}$ \\
\hline Industrias Metálicas & $0.09^{*}$ & $0.17^{*}$ & $0.22^{*}$ & $0.22^{*}$ \\
\hline Productos Metálicos & $0.02^{*}$ & $0.03^{*}$ & 0.03 & 0.03 \\
\hline Maquinaria y Eq. & $0.08^{*}$ & $0.21^{*}$ & $0.35^{*}$ & $0.37^{*}$ \\
\hline Equipo Computación & -0.01 & 0.04 & $0.12^{*}$ & $0.15^{*}$ \\
\hline Equipos Transporte & $0.06^{*}$ & $0.17^{*}$ & $0.30^{*}$ & $0.33^{*}$ \\
\hline
\end{tabular}

Nota: ${ }^{*}$ significativo al $5 \%$. 


\subsection{Sector Minería}

La minería es uno de los principales sectores analizados en este estudio. Los resultados econométricos muestran que no hay evidencia estadísticamente significativa de que los shocks en los precios del petróleo impacten en la actividad minera (principalmente extracción de petróleo). Los resultados pueden ser contra intuitivos ya que es uno de los sectores más expuestos a las variaciones en los precios internacionales. Sin embargo, este sector es ampliamente dependiente del gobierno federal, y responde principalmente a la inversión pública realizada en Pemex. Por ejemplo, con datos de la Secretaría de Hacienda y Crédito Público (SHCP) el gasto dirigido a Pemex en 2014 sumó 533 mil mdp, en 2015, 503 mdp; 2016, 495 mdp y en 2017, 382 mdp. En ese mismo periodo, el índice de actividad industrial en el sector de la minería disminuyó $21.7 \%$ con datos del INEGI. El deterioro de la actividad sectorial obedece más a los recortes en gasto que en precios por sí mismo.

Figura 8. Impulso Respuesta Sobre Actividad Minera Mrnar is

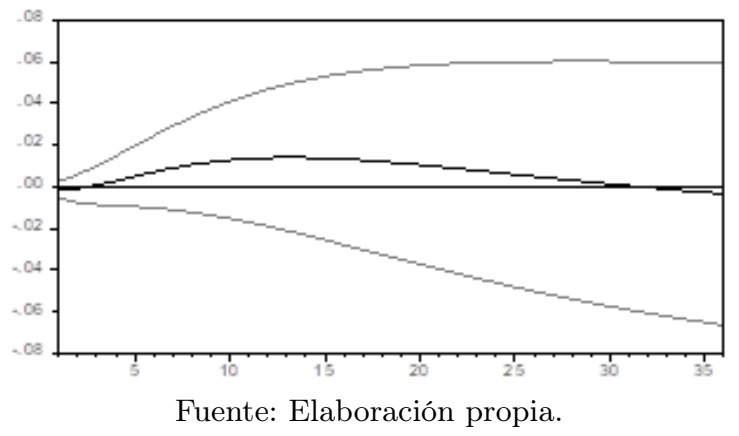

En base a la figura 8, se observa claramente que la función de impulso respuesta para la minería reacciona muy poco a precios del petróleo, y además no es estadísticamente significativa, ya que los intervalos de confianza incluyen al cero. Por ello, se genera una variante del modelo donde en lugar de regresar la actividad minera contra la actividad económica, se sustituye por una variable de gasto en el sector de Pemex. Esta variable se obtiene directamente de la Secretaría de Hacienda y Crédito Público. Para ello, se modifica ligeramente la especificación de la estructura del SVAR. Las nuevas especificaciones y restricciones se pueden encontrar en el anexo 1.5.

Figura 9. Impulso Respuesta Minería tras shock Gasto Público en Pemex Minería
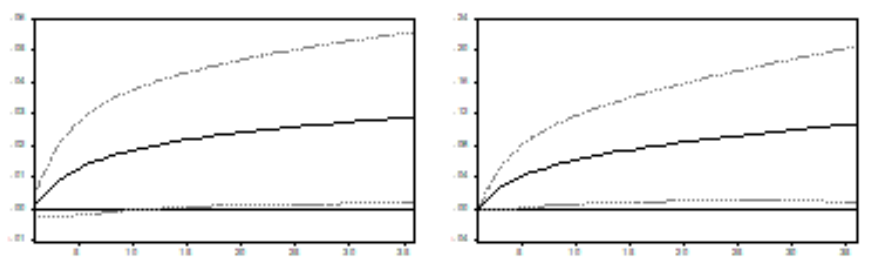

Fuente: Elaboración propia.
Servicios relacionados minería

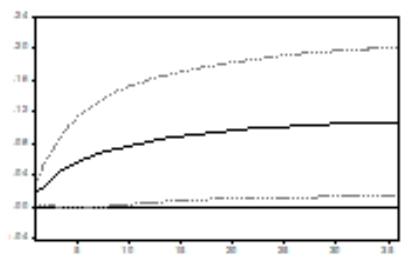

Como se observa en la figura 9, el sector de la minería reacciona positivamente ante un shock unitario en el gasto público dirigido a Pemex. Cuando se realiza el ejercicio donde la variable de impulso es el precio del petróleo, nuevamente los resultados vuelven a ser no significativos. En este sentido, la figura 9 y tabla 6 , señalan que el sector de la minería es muy dependiente de la inversión que realiza el gobierno federal en este rubro, sin importar variaciones en los precios internacionales del petróleo. Precisamente, 
REMEF (The Mexican Journal of Economics and Finance) Efecto de los precios del petróleo en la actividad económica sectorial de México.

la actividad de extracción de petróleo y gas, así como los servicios relacionados con la minería, son los subsectores con mayor dependencia del gasto público a Pemex. Los efectos para la extracción de minerales metálicos y no metálicos no resultan significativos. Los resultados se resumen en la siguiente tabla:

Tabla 6. Impacto Sector Minería Tras Shock Unitario en Gasto a Pemex

\begin{tabular}{|l|c|c|c|c|}
\hline \multicolumn{1}{|c|}{ Sector } & 6 meses & 12 meses & 24 meses & 36 meses \\
\hline Minería Total & $0.01^{*}$ & $0.02^{*}$ & $0.03^{*}$ & $0.03^{*}$ \\
\hline Extracción de Petróleo y Gas & $0.05^{*}$ & $0.07^{*}$ & $0.09^{*}$ & $0.11^{*}$ \\
\hline Extracción de Minerales & -0.00 & -0.01 & -0.01 & -0.01 \\
\hline Serv. Relacionados con Minería & $0.06^{*}$ & $0.08^{*}$ & $0.10^{*}$ & $0.11^{*}$ \\
\hline \multicolumn{2}{|r}{ Nota: ${ }^{*}$ significativo al $5 \%}$.
\end{tabular}

En general, el impacto sobre el sector de la minería es moderado tras un shock en un aumento del gasto público a Pemex, sin embargo; parte de la poca significancia en la subrama de extracción de minerales. Los impactos son considerables al analizar por sí solo a la extracción de petróleo y gas y los servicios relacionados a la minería, con impactos de 0.11 puntos porcentuales tras 36 meses del shock inicial. Los efectos de los precios del petróleo en los distintos sectores se resumen en la siguiente tabla.

Tabla 7. Impacto Precios del Petróleo a Nivel Sectorial

\begin{tabular}{|c|c|c|c|c|}
\hline & 6 meses & 12 meses & 24 meses & 36 meses \\
\hline Actividad Industrial & $0.02^{*}$ & $0.04^{*}$ & $0.07^{*}$ & $0.08^{*}$ \\
\hline Minería & 0.01 & 0.01 & 0.01 & 0 \\
\hline Extracción de Petróleo y Gas & 0.01 & 0.01 & -0.01 & -0.02 \\
\hline Minerales metálicos y no metálicos & 0 & 0.02 & 0.07 & 0.09 \\
\hline Servicios relacionados con la minería & 0.04 & 0.1 & 0.15 & 0.16 \\
\hline Gen. Electricidad, suministro agua y gas & $0.01^{*}$ & $0.04^{*}$ & 0.06 & 0.08 \\
\hline Generación, transmisión y distribución de energía eléctrica & $0.02^{*}$ & $0.06^{*}$ & $0.10^{*}$ & 0.12 \\
\hline Suministro de agua y suministro de gas & $-0.01^{*}$ & $-0.03^{*}$ & $-0.05^{*}$ & -0.05 \\
\hline Construcción & $0.03^{*}$ & $0.06^{*}$ & $0.09^{*}$ & $0.10^{*}$ \\
\hline Edificación & $0.04^{*}$ & $0.08^{*}$ & $0.11^{*}$ & $0.12^{*}$ \\
\hline Construcción de obras de ingeniería civil & 0.01 & 0.02 & 0.06 & 0.1 \\
\hline Trabajos especializados para la construcción & -0.01 & -0.02 & -0.04 & -0.04 \\
\hline Manufacturas & $0.02 *$ & $0.06^{*}$ & $0.10^{*}$ & $0.11^{*}$ \\
\hline Industria alimentaria & $0.00 *$ & $0.01^{*}$ & $0.02 *$ & 0.02 \\
\hline Industria de las bebidas y del tabaco & -0.01 & -0.01 & 0.01 & 0.02 \\
\hline Fabricación de insumos textiles & 0.02 & 0.01 & 0 & -0.01 \\
\hline Fabricación de productos textiles & $-0.04^{*}$ & -0.06 & -0.06 & -0.05 \\
\hline Fabricación de prendas de vestir & 0 & 0 & 0 & 0 \\
\hline Curtido y acabado de cuero & 0.01 & 0.01 & 0.02 & 0.02 \\
\hline Industria de la madera & 0.01 & 0.03 & 0.05 & 0.07 \\
\hline Industria del papel & 0.01 & 0.02 & 0.03 & 0.04 \\
\hline Impresión e industrias conexas & 0 & 0.04 & 0.08 & 0.08 \\
\hline Fabricación de productos derivados del petróleo y carbón & 0.01 & 0.01 & -0.02 & -0.06 \\
\hline Industria química & $0.02^{*}$ & $0.04^{*}$ & $0.04^{*}$ & 0.04 \\
\hline Industria del plástico y del hule & 0.01 & 0.04 & 0.05 & 0.06 \\
\hline Fabricación de productos a base de minerales no metálicos & 0.01 & 0.03 & $0.06^{*}$ & $0.07^{*}$ \\
\hline Industrias metálicas básicas & $0.09^{*}$ & $0.17^{*}$ & $0.22^{*}$ & $0.22^{*}$ \\
\hline Fabricación de productos metálicos & $0.02 *$ & $0.03^{*}$ & 0.03 & 0.03 \\
\hline Fabricación de maquinaria y equipo & 0.08 & $0.21^{*}$ & $0.35 *$ & $0.37^{*}$ \\
\hline Fabricación de equipo de computación, comunicación & -0.01 & 0.04 & $0.12^{*}$ & $0.15^{*}$ \\
\hline Fabricación de accesorios, aparatos eléctricos & 0.01 & 0.02 & 0.03 & 0.04 \\
\hline Fabricación de equipo de transporte & $0.06^{*}$ & $0.17^{*}$ & $0.30^{*}$ & $0.33^{*}$ \\
\hline Fabricación de muebles, equipos y persianas & 0.03 & 0.04 & 0.03 & 0.02 \\
\hline Otras industrias manufactureras & 0 & 0.01 & 0.04 & 0.06 \\
\hline
\end{tabular}

Nota: * significativo al $5 \%$

La tabla 7 resume el impacto en la actividad de cada uno de los sectores industriales de la economía mexicana tras un shock unitario en los precios del petróleo. Como se observa a nivel general el impacto es significativo. Adicionalmente, a nivel agregado la 
construcción y manufacturas también son significativas. Sin embargo, dentro del sector de las manufacturas encontramos heterogeneidad y algunos subsectores responden a variaciones en el precio del petróleo. Como se dijo anteriormente, la minería no responde a shocks en precios, aunque esto cambia cuando se anexa la variable de gasto en Pemex en el modelo.

\section{Conclusión}

La dinámica de los precios del petróleo tiene diversos efectos tanto en las ramas económicas analizadas (minería, generación de electricidad, suministro de agua y gas, construcción y manufacturas) como en los 29 sectores económicos que componen dichas ramas.

Esta investigación muestra que las variaciones en los precios del petróleo afectan la actividad industrial. Además, el tipo de cambio se aprecia tras este shock. Trabajos como Kohlscheen et al. (2016), muestran una relación inversa entre los precios del petróleo y tipo de cambio, por lo que un aumento del primero lleva a una apreciación del segundo. El nivel de precios se presiona ligeramente, con lo cual el nivel de las tasas de interés sube. A nivel sectorial, la fabricación de maquinaria y equipo y la fabricación de equipo de transporte resultan ser los más beneficiados en este estudio. Estos sectores se caracterizan por un alto contenido de insumos importados, y las apreciaciones de la moneda nacional favorecen la competitividad y disminuyen los costos de producción. Por otra parte, los resultados de este estudio también indican que existen otros sectores económicos que reaccionan de forma contra cíclica; por ejemplo, el suministro de agua y gas y la fabricación de productos textiles. Todo esto muestra la heterogeneidad de la industria, en donde incluso algunos sectores no reaccionan ante variaciones en precios del crudo.

Un hallazgo relevante es el hecho de que el sector de la minería, principalmente extracción de petróleo y gas, así como los servicios relacionados con la minería, no responden a variaciones en precios del petróleo. Cuando se ajusta el modelo incluyendo el gasto público en Pemex, el efecto es relevante sobre la actividad sectorial, aunque nuevamente los precios del crudo no tienen efectos significativos. Sin duda, el papel que juega el gasto público es de vital importancia para el sector extractivo, por lo cual es recomendable evitar fuertes recortes en el mismo.

Debido a que la literatura no es abundante en lo que respecta al análisis del efecto de los precios del petróleo en los sectores económicos, se espera que la presente investigación pueda motivar al desarrollo de futuras investigaciones en esta área. Entre los temas propuestos para futuras investigaciones se encuentran el análisis de asimetrías de reacción dentro de un mismo sector económico ante shocks positivos y negativos; así como el analizar como la apertura petrolera y el aumento de competitividad esperado en este sector pueden afectar el traspaso a los diferentes sectores de la economía mexicana. 
REMEF (The Mexican Journal of Economics and Finance)

Efecto de los precios del petróleo en la actividad económica sectorial de México.

\section{Referencias}

Alarco, G. (2006). La evolución del precio del petróleo crudo y la economía de México, 1975-2004. Comercio exterior, 56(9), 930-944.

Alonso, J., Martínez, D. (2017). Impacto del precio del petróleo sobre el PIB de los países de la Alianza del Pacífico. Revista Finanzas y Política Económica, 9 (2), 249-264

Akram, H. (2011). Do crude oil price affect economic growth of India, Pakistan and Bangladesh? A multivariate time series analysis. Hogskolan Dalarna Economics D-Level Thesis.

Al-Mawali, N., Hasim, H. M., Al-Busaidi, K. (2016). Modelling the impact of the oil sector on the economy of sultanate of Oman. International Journal of Energy Economics and Policy, 6(1), 120-127.

Ashgar, N., Ahmed, T. (2015). Pass Through of World Oil Prices to Inflation: A Time Series Analysis of Pakistan Nabila, Pakistan. Economic and Social Review, 53(2), 269-284.

Baumeister, C., Peersman, G. (2012). Time Varying Effects of Oil Supply Shocks on the US Economy. Bank of Canada Working Paper 2012-2.

Blanchard, O., Galsi, J. (2007). The macroeconomic effect of oil shocks: Why are the 2000s so different from the 1970s? NBER Working Paper Series No. 13368.

Blanchard, O., Galsi, J. (2009). Why are the 2000s so different from the 1970s? A Structural Interpretation of Changes in The Macroeconomic Effects of Oil Prices. NBER Working Paper Series No. 15467.

Boheman, H., Maxen, J. (2015). Oil Price Shocks Effect on Economic Growth, OPEC versus non-OPEC Economies. Lund University.

Campos, P. (2016). Whatever Happened to the Mexican Oil Bonanza: The Challenges of Mexico's New Oil Fund. Natural. Resources Journal, 56(2), 291-312.

Capistrán, C., Ibarra, R., Ramos, M. (2012). El traspaso de movimientos del tipo de cambio a los precios: un análisis para la economía mexicana. El Trimestre Económico, 79(4), 813-838.

Cortés, J. (2013). Una Estimación del Traspaso de las Variaciones en el Tipo de Cambio a los Precios en México. Research Document No. 2013-02, Banco de México.

Craveiro, F. (2013). Oil price shocks and their effects on economic activity and prices: An Application for Portugal. Banco de Portugal. Economic Bulletin Summer 2013, 39-48

Cuñado, J., Pérez, F. (2003). Do Oil Price Shocks Matter? Evidence for Some European Countries. Energy Economics, 25, 137-154.

Difiglio, C. (2014). Oil, economic growth and strategic petroleum stocks. Energy Strategy Review, 5, 48-58.

Farhani, S. (2012). Impact of Oil Price Increases on US Economic Growth: Causality Analysis and Study of the Weakenings Effects in Relationship. International Journal of Energy Economics and Policiy, $2(3), 108-122$.

González, A., Nabiyev, S. (2009). Oil price fluctuations and its effect on GDP growth. A case study of USA and Sweden. Jonkoping International Business School.

González, J., Saucedo, E. (2018). Traspaso Depreciación-Inflación en México: Análisis de Precios al Consumidor y Productor. Revista de Economía y Finanzas Nueva Época REMEF (The Mexican Journal of Economics and Finance), 13(4), 525-545, doi: http://dx.doi.org/10.21919/remef.v13i4.337.

González S. (2015). Impacto de los precios del petróleo sobre el crecimiento económico, evidencia para Colombia (1982-2013) (Doctoral dissertation, Universidad Nacional de Colombia).

Griffin, J. M., Teece, D. J. (2016). OPEC behaviour and world oil prices. Routledge Books.

Hahn, E., Mestre, R. (2011). The Role of Oil Prices in the Euro Area Economy Since the 1970. European Central Bank, Working Paper Series 1356.

Hamilton, J. (1983). Oil and the Macroeconomy Since World War II. Journal of Political Economy, 91, 228-248.

Hartley, P., Medlock III, K. (2011). The Revenue Efficiency of Pemex: A Comparative Approach.

IMF Research Department (2000). The Impact of Higher Oil Prices on the Global Economy. Policy Papers.

Jiménez, R. (2011). Macroeconomic Structure and Oil Price Shocks at the Industrial Level. International Economic Journal, 25(1), 173-189.

Killian, L. (2008). The Economic Effects of Energy Price Shocks. Journal of Economics Literature, 46(4), 871-909.

King, K., Deng, A., Metz, D. (2012). An econometric analysis of oil price movements: the role of political events and economic news, financial trading, and market fundamentals. Bates White Economic Consulting.

Kohlscheen, E., Avalos, F., Schrimpf, A. (2016). When the Walk is not Random: Commodity Prices and Exchange Rates. BIS Working Papers 551.

Lanceri, L. (2014). Determinantes de los precios reales del petróleo y su impacto sobre las principales variables macroeconómicas: EU, España, Noruega y Argentina. Economía: Teoría y Práctica. Nueva Época, 41, 45-70.

Lizardo, R., Mollick, A. (2010). Oil price fluctuations and US dollar exchange rates. Energy Economics, $32(2), 399-408$. 
Lorenzo Valdés, A., Durán Vázquez, R., Armenta Fraire, L. (2017). Çonditional Correlation Between Oil and Stock Market Returns: The Case of Mexico ". Revista Mexicana de Economía y Finanzas Nueva Época REMEF (The Mexican Journal of Economics and Finance), 7(1). doi: http://dx . doi.org/10.21919/remef.v7i1.28.

Mohaddes, K., Pesaran, M. (2016). Oil Prices and the Global Economy: Is It Different This Time Around? IMF Working Paper, WP/16/20.

Pedersen, M., Ricaurte, M. (2014). Efectos de Shocks al Precio del Petróleo Sobre la Economía de Chile y sus Socios Comerciales. Economía Chilena, 17(1), 38-65.

Peersman, G., Van Robays, I. (2009). Oil and the Euro area economy. Economic Policy, 24(60), 603-651.

Perilla, J. (2010). El impacto de los precios del petróleo sobre el crecimiento económico en Colombia. Revista de Economía del Rosario, 13(1), 75-116.

Ramírez, C. (2014). La Enfermedad Holandesa en México 1995-2014, (Tesis doctoral, El Colegio de la Frontera Norte).

Reyes, M.R., Benítez, N.P. (2016). Las implicaciones del ajuste económico para 2016. Revista Pluralidad y Consenso, 6(27).

Santillán, S., Venegas, F. (2015). Impact of Oil Prices on Economic Growth in Latin American Oil Exporting Countries (1990-2014): A Panel Data Analysis. Available at SSRN: https://ssrn.com/ abstract=2692024orhttp: //dx. doi .org/10.2139/ssrn . 2692024 .

Sieminski, A. (2014). International Energy Outlook. Energy Information Administration (EIA).

Sotoudeh, M., Worthington, A. (2017). Responses of Economic Activity to Global Oil Market Shocks: A Comparative Analysis of Major Net Oil-Producing and-Consuming Countries. Economic Record.

Schwartz, M., Tijerina, A., Torre, L. (2002). Volatilidad del tipo de cambio y tasas de interés en México: 1996-2001. Economía Mexicana Nueva Época, 11(2), 299-331. 
REMEF (The Mexican Journal of Economics and Finance)

Efecto de los precios del petróleo en la actividad económica sectorial de México. Análisis para el periodo 2002-2018

\section{Anexos}

1.1 Sectores: Se presentan los sectores de la actividad industrial enlistados del INEGI.

\begin{tabular}{|c|l|c|l|}
\hline Clasificación & \multicolumn{1}{|c|}{ Nombre INEGI } & Clasificación & \multicolumn{1}{c|}{ Nombre INEGI } \\
\hline & Industria Total & 13 & Fabricación de prendas de vestir \\
\hline & Minería & 14 & Curtido y acabado de cuero \\
\hline 1 & Extracción de Petróleo y Gas & 15 & Industria de la madera \\
\hline 3 & Minerales metálicos y no metálicos & 16 & Industria del papel \\
\hline & Servicios relacionados con la minería & 17 & Impresión e industrias conexas \\
\hline 4 & Gen. de electricidad y suministro de gas & 18 & Fab. productos derivados petróleo y carbón \\
\hline 5 & Gen. Trans y Dist. de energía eléctrica & 19 & Industria química \\
\hline & Suministro de agua y suministro de gas & 20 & Industria del plástico y del hule \\
\hline 6 & Construcción & 21 & Fab. productos de minerales no metálicos \\
\hline 7 & Edificación & 22 & Industrias metálicas básicas \\
\hline 8 & Construcción de obras de ingeniería civil & 23 & Fabricación de productos metálicos \\
\hline & Trabajos especializados para la construcción & 24 & Fabricación de maquinaria y equipo \\
\hline 9 & Industrias Manufactureras & 25 & Fabricación eq. computación, comunicación \\
\hline 10 & Industria alimentaria & 26 & Fabricación de accesorios, aparatos eléctricos \\
\hline 11 & Industria de las bebidas y del tabaco & 27 & Fabricación de equipo de transporte \\
\hline 12 & Fabricación de insumos textiles & 28 & Fabricación de muebles, equipos y persianas \\
\hline Fabricación de productos textiles & 29 & Otras industrias manufactureras \\
\hline
\end{tabular}

Solo se numeran los subsectores de cada sector industrial (minería, generación electricidad y suministro de agua y gas, construcción y manufacturas).

1.2 Pruebas de Cointegración: Con la finalidad de detectar si existe relación de largo plazo entre las variables del modelo, se realizaron pruebas de cointegración a través de pruebas de Johansen. Los resultados se encuentran en la tabla de abajo y demuestran que, en la mayoría de los sectores, no existe un vector de cointegración entre las variables del precio del petróleo, actividad económica, tasas de interés, inflación y tipo de cambio. Por consecuencia, es inapropiado establecer un Modelo de Vector de Corrección del Error (VEC).

Test de Cointegración

Variables: Actividad Económica, Inflación, Tasa de Interés, Tipo de Cambio, WTI, Actividad Sectorial Unrestricted Cointegration Rank Test (Trace)

\begin{tabular}{|c|c|c|c|c|}
\hline & $\begin{array}{l}\text { Ningún } \\
\text { Vector }\end{array}$ & Al Menos 1 & Al Menos 2 & $\begin{array}{c}\text { Vectores } \\
\text { Cointegración }\end{array}$ \\
\hline Industria Total & 0.8176 & 0.9284 & 0.7203 & 0 \\
\hline Minería & 0.6177 & 0.5094 & 0.8640 & 0 \\
\hline Extracción de Petróleo y Gas & 0.4387 & 0.4542 & 0.7584 & 0 \\
\hline Minerales metálicos y no metálicos & 0.8708 & 0.8135 & 0.9230 & 0 \\
\hline Servicios relacionados con la minería & 0.0152 & 0.2551 & 0.1603 & 1 \\
\hline Gen. electricidad, suministro agua y gas & 0.5642 & 0.7027 & 0.2965 & 0 \\
\hline Gen., trans. distribución de energía eléctrica & 0.5467 & 0.7220 & 0.3243 & 0 \\
\hline Suministro de agua y suministro de gas & 0.0435 & 0.4290 & 0.1129 & 1 \\
\hline Construcción & 0.3360 & 0.8633 & 0.5416 & 0 \\
\hline Edificación & 0.7743 & 0.8686 & 0.2484 & 0 \\
\hline Construcción de obras de ingeniería civil & 0.0167 & 0.1445 & 0.1545 & 0 \\
\hline Trabajos especializados para construcción & 0.5696 & 0.8412 & 0.3958 & 0 \\
\hline Manufacturas & 0.8536 & 0.9635 & 0.3754 & 0 \\
\hline Industria alimentaria & 0.0481 & 0.2780 & 0.4618 & 1 \\
\hline Industria de las bebidas y del tabaco & 0.4415 & 0.8032 & 0.8543 & 0 \\
\hline Fabricación de insumos textiles & 0.0110 & 0.2736 & 0.1262 & 1 \\
\hline Fabricación de productos textiles & 0.3585 & 0.6511 & 0.2457 & 0 \\
\hline Fabricación de prendas de vestir & 0.1215 & 0.4913 & 0.1491 & 0 \\
\hline Curtido y acabado de cuero & 0.1429 & 0.4071 & 0.0721 & 0 \\
\hline Industria de la madera & 0.2216 & 0.2632 & 0.0424 & 0 \\
\hline Industria del papel & 0.3506 & 0.9096 & 0.9221 & 0 \\
\hline Impresión e industrias conexas & 0.5970 & 0.6084 & 0.2533 & 0 \\
\hline Fab. Prod. derivados del petróleo y carbón & 0.9210 & 0.8946 & 0.8864 & 0 \\
\hline Industria química & 0.2978 & 0.5891 & 0.2373 & 0 \\
\hline Industria del plástico y del hule & 0.9357 & 0.9852 & 0.9509 & 0 \\
\hline Fab. productos de minerales no metálicos & 0.3769 & 0.6494 & 0.2905 & 0 \\
\hline Industrias metálicas básicas & 0.8856 & 0.9810 & 0.4670 & 0 \\
\hline Fabricación de productos metálicos & 0.7721 & 0.9842 & 0.8873 & 0 \\
\hline Fabricación de maquinaria y equipo & 0.8880 & 0.9695 & 0.9049 & 0 \\
\hline Fab. equipo de computación, comunicación & 0.7760 & 0.9464 & 0.3574 & 0 \\
\hline Fab. de accesorios, aparatos eléctricos & 0.5562 & 0.9693 & 0.5643 & 0 \\
\hline Fabricación de equipo de transporte & 0.9334 & 0.9554 & 0.4909 & 0 \\
\hline Fabricación de muebles, equipos y persianas & 0.0570 & 0.6970 & 0.2842 & 0 \\
\hline Otras industrias manufactureras & 0.8791 & 0.9447 & 0.9343 & 0 \\
\hline
\end{tabular}

La prueba de cointegración es un Test de Johansen. La hipótesis nula significa que las variables no están 
cointegradas. Las columnas muestran sí existe evidencia significativa de que no existe un vector de cointegración, al menos uno o al menos dos. De lado derecho se muestra el número de vectores encontrados que cointegran.

A pesar de que en algunos sectores sí existe al menos un vector de cointegración, se decidió proceder a construir un modelo VAR para cada sector, con la finalidad de ser congruentes y comparables los resultados entre sectores.

\subsection{Prueba de Exogeneidad (Test de Granger)}

La hipótesis nula es que las variables en las columnas no causan en el sentido de Granger al precio del petróleo.

\begin{tabular}{|l|c|c|c|c|c|c|}
\hline & IGAE & INPC & CETE & TC & PEMEX & MINERIA \\
\hline Precio Petróleo & 0.68 & 0.14 & 0.17 & $0.02^{*}$ & 0.29 & 0.79 \\
\hline \multicolumn{7}{|c|}{ Fuente: Elaboración propia. }
\end{tabular}

Todas ellas (no se puede rechazar Ho) no causan en el sentido de Granger al precio del petróleo, con excepción del tipo de cambio que al nivel del $5 \%$ causa en el sentido de Granger a los precios. Para ello se asumió que el precio internacional es una variable exógena en el modelo implementado en esta investigación.

\subsection{Gráficas Impulso Respuesta:}

La línea central representa la función de impulso respuesta de cada sector. Las líneas punteadas representan el intervalo de confianza al $95 \%$. Se presenta un plazo de 36 meses para cuantificar el impacto de un shock unitario en precio del petróleo sobre la actividad sectorial.

Reacción en la Actividad Sectorial tras Shock Unitario en Precio Petróleo Industia 1 Extracción de Peróleo y Gas Industria 2: Minerales metálicos y no Industria 3: Servicios relac ionados con la
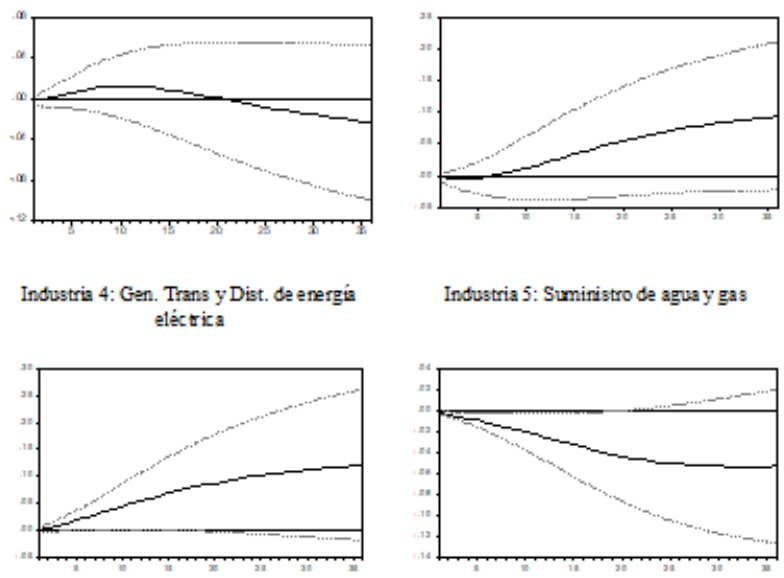

eléctrica
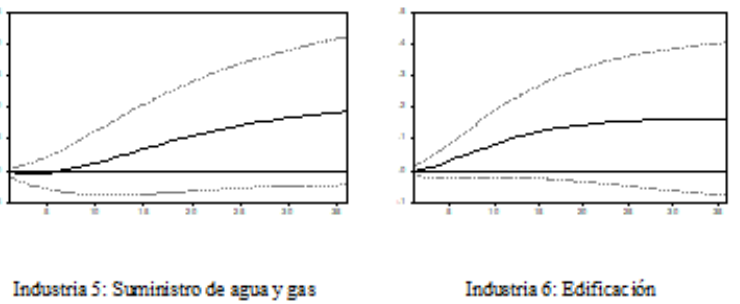

Industria 5: Suministro de agua y gas

Industria 6: Edificación
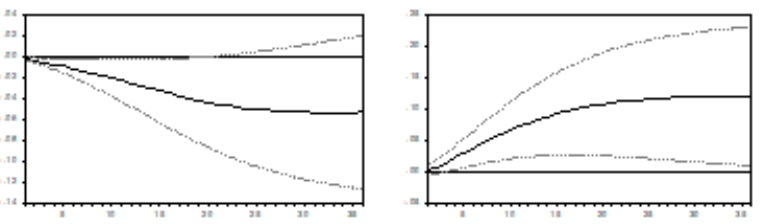

Industria 7: Construcción de doras de ingenieria civil

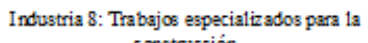
construcción
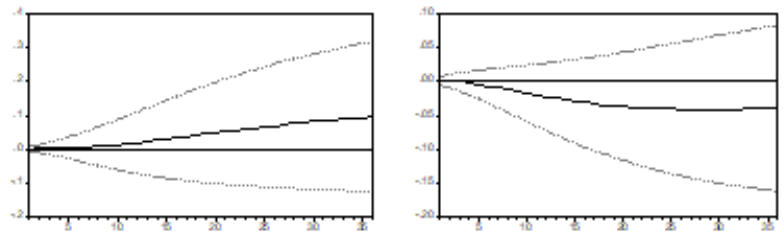

Industria 9: Industria alimentaria

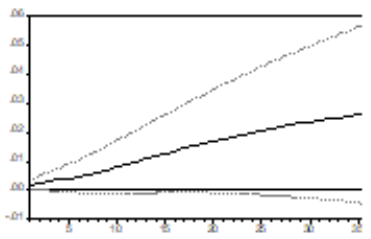


REMEF (The Mexican Journal of Economics and Finance) Efecto de los precios del petróleo en la actividad económica sectorial de México. Análisis para el periodo 2002-2018

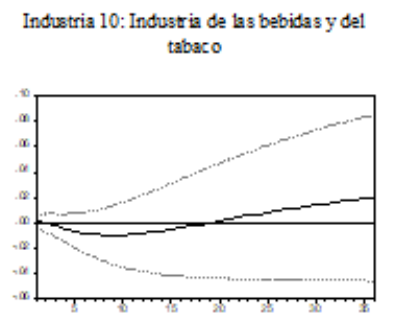

Industria 11: Fabric ación de insumos textiles

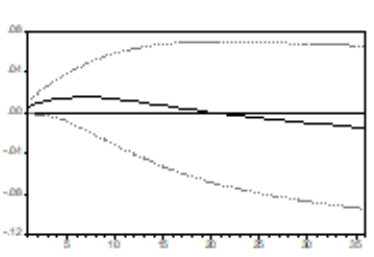

Industria 14: Curtido y ac abado de cvero

Industria 13: Fabricación de prendas de vestir
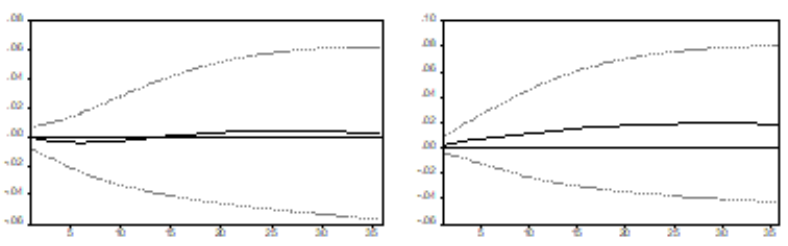

Industria 12: Fabricación de produc tos textiles

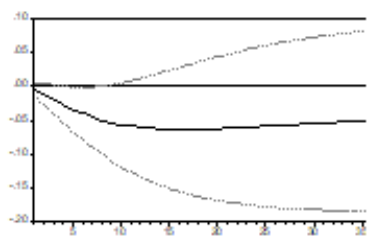

Industria 15 : Industria de la madera

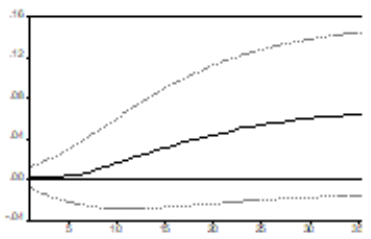

Gráficas Impulso Respuesta (Continuación)

Industria 16: Industria del papel

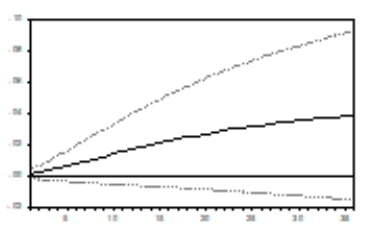

Industria 19: Industria quimica

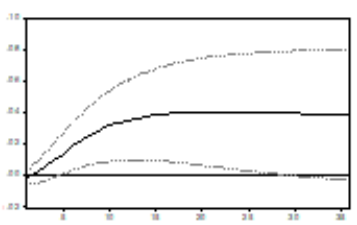

Industria 22: Industria s me tálicas básic as

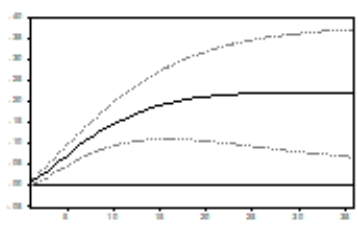

Industria 25: Fabricación eq. computación, comunicaciớn

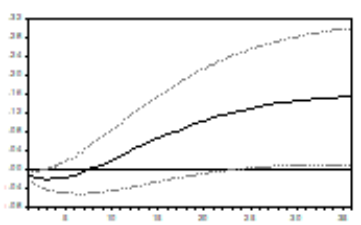

Industria 17: Impresión e industrias conexas

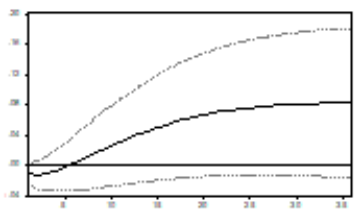

Industria 20: Industria del plástic o y del hul

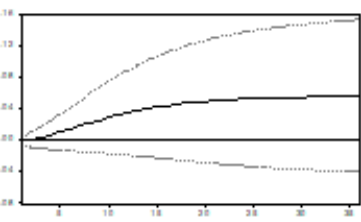

Industia 23: Fabricación de productos metálic $\propto s$

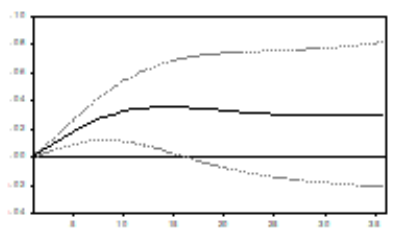

Industria 26: Fabricación de accesorios, apara tos eléctricos

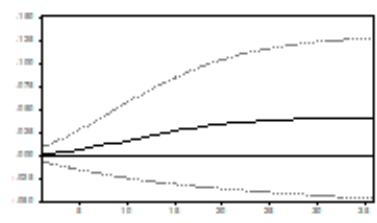

Industria 18: Fab. productos deriva dos petróleo y carbón

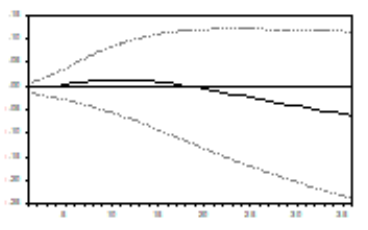

Industria 21: Fab. productos de minerales no metálicos

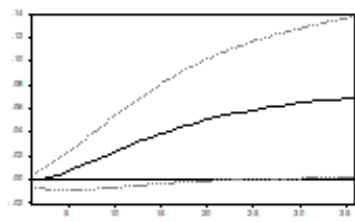

Industria 24: Fabricación de maquinaria y equipo

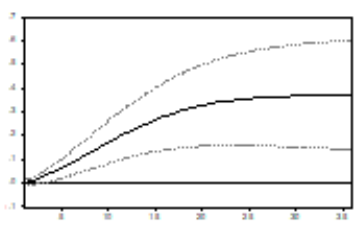

Industria 27: Fabricación de equipo de transporte

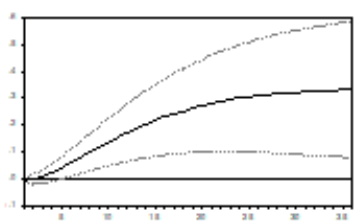


Revista Mexicana de Economía y Finanzas Nueva Época, Vol. 14 No. 2, pp. 221-243

Industria 28: Fabricación de muebles, equipos y persianas

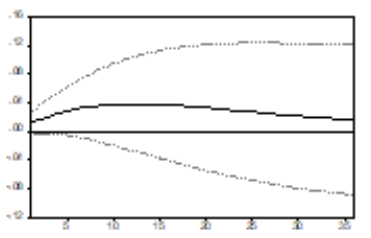

Gen. Elect. Sum. Agua y Gas

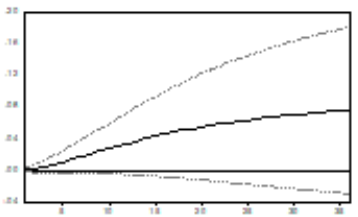

Industria 29: Otras industrias manufac tureras

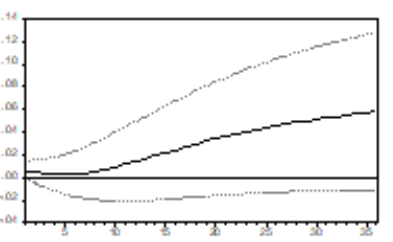

Construcción

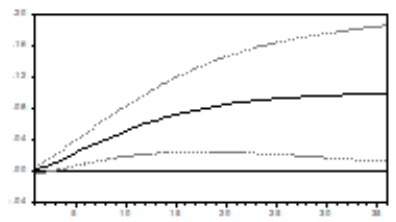

Mineria

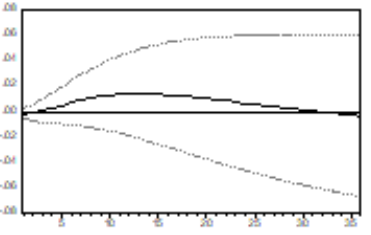

Manufacturas

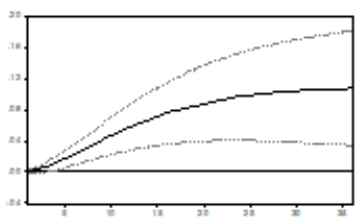

Fuente: Elaboración propia.

\subsection{Matriz Pemex}

Se presenta una matriz de tamaño 6x6 que engloba a las variables presentadas en el modelo SVAR. Se busca medir las perturbaciones de $u_{t}$ que están relacionadas a shocks $\varepsilon_{t}$ en las variables macroeconómicas a través de la matriz $A_{0}$, tal que: $A_{0} u_{t}=\varepsilon_{t}$. Se utiliza una estructura no recursiva, y esto asume restricciones en los efectos contemporáneos tras shocks estructurales. Con ello la matriz $A_{0}$ queda representada de la siguiente manera:

$$
\left[\begin{array}{cccccc}
a_{1} & 0 & a_{2} & 0 & a_{3} & 0 \\
0 & a_{5} & 0 & a_{6} & a_{7} & 0 \\
0 & 0 & a_{8} & a_{9} & a_{10} & 0 \\
0 & a_{12} & a_{13} & a_{14} & a_{15} & 0 \\
0 & 0 & 0 & 0 & a_{16} & 0 \\
a_{17} & a_{18} & a_{19} & a_{20} & a_{21} & a_{22}
\end{array}\right]\left[\begin{array}{c}
u_{t}^{\text {pemex }} \\
u_{t}^{\text {inf }} \\
u_{t}^{r} \\
u_{t}^{t c} \\
u_{t}^{\text {oil }} \\
u_{t}^{\text {minera }}
\end{array}\right]=\left[\begin{array}{c}
\varepsilon_{t}^{\text {pemex }} \\
\varepsilon_{t}^{\text {inf }} \\
\varepsilon_{t}^{r} \\
\varepsilon_{t}^{t c} \\
\varepsilon_{t}^{\text {oil }} \\
\varepsilon_{t}^{\text {minera }}
\end{array}\right]
$$

La intuición es la misma que presentada en el cuerpo del texto, se asume que el gasto gubernamental destinado a Pemex es sensible ante shocks en la tasa de interés (gobierno debe modificar el gasto ante mayor endeudamiento por sus pasivos) y ante cambios en el precio del petróleo. De la misma manera, shocks en el gasto a Pemex impacta al sector de la minería, pero no al resto de las variables macroeconómicas. Se realizaron pruebas de robustez, consúltese con autores. 